\title{
LA ERA MENEMISTA DEL PAMI. UNA APROXIMACIÓN AL PASADO RECIENTE DE LA OBRA SOCIAL DE LOS JUBILADOS EN ARGENTINA
}

\author{
The Menem's age of the PAMI. An approach to the recent history of the medical \\ insurance for the retirees in Argentina
}

Sol Minoldo*

\section{Resumen}

Orientado principalmente a la cobertura de personas jubiladas, el PAMI constituye una institución clave en la mediación del acceso de las personas mayores argentinas a la cobertura de salud. Sin embargo, los antecedentes de estudio específicamente centrados en este organismo son llamativamente escasos. Este trabajo propone reconstruir una aproximación a la etapa de gestión menemista del instituto a través del relato documentado de la prensa escrita. Para ello, sistematiza la información publicada por tres periódicos de tirada nacional con diferentes líneas editoriales (La Nación, Página12 y Clarín). En el periodo de 6 años que abarca el análisis, se implementaron en PAMI diferentes modelos de gestión y de gobierno, el organismo acumuló una deuda asfixiante, la salud de las personas mayores fue puesta en riesgo debido a reiteradas interrupciones de la atención así como a diversas falencias y demoras, y fue afectada fuertemente la estructura y economía del sistema nacional de prestadores de salud.

$$
<\text { PAMI }><\text { INSSJP }><\text { Salud }><\text { Personas mayores }>
$$

\begin{abstract}
PAMI, as an institution destined to pension people, is a key institution to guarantee the access of the elderly to health services. However, the scientific literature centred on PAMI is remarkable limited. This paper proposes to reconstruct an approach to the Menem's age on PAMI trough newspapers reports. Hence, it systematizes the information published in three national newspapers with different editorial lines (La Nación, Página12 y Clarín). During the 6 years analyzed, PAMI implemented different management and government styles. It had accumulated a huge debt, threatened the elderly health because of lack or delay on the attention, and impacted over the structure and economy of the health national system.
\end{abstract}

$$
<\text { PAMI }><\text { INSSJP }><\text { Health }><\text { Elderly }>
$$

Recibido: 30/06/2018 //Aceptado: 02/09/2018

* Universidad Nacional de Córdoba (UNC), Argentina. Centro de Investigaciones y Estudios sobre Cultura y Sociedad (CIECS), Investigadora Asistente del Consejo Nacional de Investigaciones Científicas y Técnicas (CONICET), solminoldo@gmail.com 
Minoldo. La era menemista del PAMI. Una aproximación al pasado reciente de la obra social de los jubilados en...

\section{Introducción}

El Instituto Nacional de Servicios Sociales para Jubilados y Pensionados (INSSJP) más conocido como PAMI, ${ }^{1}$ constituye la obra social más grande, no sólo de Argentina, sino de Latinoamérica. Orientada principalmente a la cobertura de personas jubiladas, constituye además una institución clave en la mediación del acceso de las personas mayores a la cobertura de salud.

A pesar de la inmensa importancia de PAMI, -tanto por sus enormes dimensiones institucionales y económicas como por la relevancia de los servicios de los que es responsabilizarse y la cantidad de personas cuyos derechos de acceso a la salud son mediados por el instituto- los antecedentes de estudio específicamente centrados en PAMI son llamativamente escasos. La revisión académica arroja apenas algunos materiales sin continuidad en el tiempo. Se trata de un tema de investigación que, sin dudas, amerita una mayor atención pero cuyo abordaje redunda en dificultades, precisamente, por tratarse de un campo prácticamente inexplorado. Por todo ello, este trabajo, adquiere especial relevancia por el tema del que se ocupa y por lo que puede implicar para alentar futuros estudios del mismo.

En la medida que PAMI ha ocupado la agenda mediática de manera persistente en los años menemistas, la prensa escrita constituye una base documental relevante. Por ello, este documento propone reconstruir una aproximación a una etapa de la historia del instituto a través del relato de la prensa escrita, sistematizando la información publicada por tres periódicos de tirada nacional con diferentes líneas editoriales (La Nación, Página12 y Clarín). El trabajo se basa en la información obtenida de todos los artículos que publicaron encontrados en los tres periódicos con relación a PAMI, entre 1994 y 1999 (344 artículos en total).

A mediados de los años 90s PAMI se instaló en la prensa a partir de dos principales ejes: sus falencias para garantizar el acceso a la salud de las personas mayores y, en simultáneo, la denuncia de escándalos de corrupción, enfocados no sólo como una fuente de despilfarro y pérdida de recursos sino como el eje que estructuraba la administración propia de PAMI y explicaba principalmente sus fracasos para los usuarios. La agenda mediática de la corrupción trascendía el caso de PAMI en los 90s, pero PAMI constituía un caso testigo que contaba con el dramatismo de sus palpables consecuencias para la salud de los más viejos. Aunque el interés de los tres diferentes medios de prensa analizados no era exactamente el mismo, había coincidencia en estos ejes principales.

El periodo analizado corresponde a la gestión menemista, por lo que el punto de llegada es el cambio de gobierno. Sin embargo, como punto de partida se escogió el año 1994, debido a la inauguración de la mediatización de los casos de corrupción en PAMI, durante la gestión de Matilde Menéndez.

Antes conocido como Programa de Asistencia Médica Integral (PAMI) y posteriormente re-bautizado "Por Argentina con Mayores Integrados" mediante la Resolución N 654/DE/2009 (Gragnolati et al, 2014). 
Si bien el trabajo constituye ante todo la reconstrucción de una mirada determinada (mediática) de los hechos, aporta valiosos contenidos para registrar acontecimientos histórica e institucionalmente relevantes en PAMI, contribuyendo así a disponer de una primera aproximación de los derroteros del instituto en una etapa crítica. En los 6 años del análisis se experimentaron diferentes modelos de gestión y de gobierno del instituto, se estuvo a punto de proceder a su disolución, se acumuló una deuda asfixiante, se puso en riesgo la salud de los adultos mayores con interrupciones de la atención de la salud y diversas falencias y demoras en la atención, y se afectó fuertemente la estructura y economía del sistema nacional de prestadores de salud.

En la medida que el objetivo es reconstruir la historia de PAMI, el énfasis no se encuentra en diferenciar la mirada de cada medio de prensa, sino en tomar de cada uno los aportes que pueden enriquecer la información. De todas maneras cabe advertir que, como puede apreciarse en la información sobre las fuentes, la información sobre PAMI fue mucho más abundante en diario La Nación y en segundo lugar en Clarín, siendo Página 12 el periódico que menos artículos dedicó al tema en el periodo de estudio. Para articular y exponer el material, la información fue organizada de manera cronológica empleando como hilo conductor las sucesivas administraciones políticas de PAMI en el periodo.

\section{EI PAMI y la protección de la salud de las personas mayores en Argentina}

Si bien la salud es importante en todas las etapas de la vida, la vejez suele llegar acompañada de un incremento de las necesidades de protección de la salud: las dolencias, enfermedades y formas de discapacidad que abundan en el último tramo de la vida, se tornan aspectos prioritarios en la definición de la calidad de vida de las personas mayores.

En Argentina, la protección de la salud de las personas mayores se inserta en un complejo sistema de salud compuesto por diferentes sectores escasamente articulados entre sí: (1) el sector público, (2) las obras sociales (que se financia con el aporte de los trabajadores y empleadores) y (3) el sector privado. "El sistema se caracteriza por la segmentación, fragmentación y heterogeneidad” (Bursztyn et al, 2010: 81). Entre estos tres sistemas se produce frecuentemente la superposición de cobertura y prestaciones de calidad diferencial, especialmente debido a dispares niveles de financiamiento.

El sector público de salud protege en teoría al 100\% de la población, dado que toda persona tiene derecho a acceder gratuitamente a su atención. Sin embargo, en los hechos la mayor parte de la demanda al sector público tiene que ver con un $38 \%$ de la población que no cuenta con ningún otro tipo de cobertura. De este modo, "si bien tienen como objetivo brindar cobertura universal a toda la población, se constituyen en prestadores de última instancia de la población sin cobertura formal de la seguridad social" (Maceira, 2003: 6). Por su parte, las obras sociales dan cobertura a todos los trabajadores en relación de dependencia en el mercado de trabajo privado formal, a los trabajadores del sector público provincial y nacional y a las familias (cónyuge, hijos y otros familiares a cargo) de todos esos trabajadores. Existe además una obra social que proporciona cobertura a todos los trabajadores jubilados y pensionados: PAMI. Según 
Minoldo. La era menemista del PAMI. Una aproximación al pasado reciente de la obra social de los jubilados en...

se deduce de los datos aportados por Anlló y Cetrángolo (2007: 415), las obras sociales cubrían en 2006 el 52\% de la población. En tanto PAMI, la más grande de estas obras sociales, cubría en 2006 al 9\% de la población.

PAMI constituye el eje central de la protección de la salud de la tercera edad en Argentina ya que "brinda cobertura al $82 \%$ de las personas mayores de 64 años y a más del 96\% de las personas mayores de 79 años de la Argentina" (INSSJP, 2012: 6). De este modo, la comprensión y explicación de la dinámica y resultados de PAMI reportan una importancia fundamental para el estudio de la protección sanitaria de las personas mayores en el país.

Para poder comprender PAMI es necesario primero situarlo en el contexto del resto de las obras sociales. Es allí que tienen raíz algunos de sus rasgos fundamentales, y en donde emergen los primeros signos de la relevancia que tiene, para el estudio de la institución, la dinámica política que atraviesa tanto la conducción como el tipo de procedimientos, medidas, alianzas y negocios con el sector privado que se configuran en este tipo de instituciones.

El sistema de obras sociales se institucionalizó en Argentina 1970 con la Ley 18.610, que generalizaba la cobertura de las obras sociales a la totalidad de la población en relación de dependencia haciendo obligatoria la afiliación de cada trabajador a la obra social correspondiente a su rama de actividad. "Teniendo en cuenta que la organización sindical argentina respondió a un modelo de gremio único por rama de actividad, ello significó, en la práctica, la transformación de la población trabajadora en cautiva de la obra social del gremio correspondiente" (Anlló y Cetrángolo, 2007: 399). Con ello, el control de obras sociales se convirtió paulatinamente en fuente de poder político y económico para los sindicatos (Belmartino, 2005). Por su parte, la Ley 19.032 extendió en 1971 el sistema de obras sociales a los jubilados y pensionados, creando una institución especial, el Instituto Nacional de Servicios Sociales para Jubilados y Pensionados (INSSJP), conocido comúnmente con el nombre de PAMI.

Lloyd-Sherlock (1997) apunta que la información acerca del desempeño de PAMI en los 70 s y 80 s es muy restringida, debido a que no se requería al instituto someterse a auditorías externas, ni siquiera por parte del gobierno, en virtud de su autonomía. Según el autor, la única excepción en tal sentido es el trabajo de Laura Golbert (1988) que analiza el funcionamiento del organismo en algunos años de los 80s. Dicho análisis da cuenta de la aparición de algunas dificultades del organismo, ya desde 1983, para cubrir sus propias erogaciones. Asimismo, Lloyd-Sherlock (1997) describe un proceso de incremento de las erogaciones de PAMI hacia finales de los 80 s, en parte por incrementos de la cobertura y en parte por la expansión de los beneficios y servicios proporcionados a los afiliados, incluyendo subsidios a la pobreza. Al llegar el año 1994, cuando comenzaron a realizarse auditorías externas, salieron a la luz problemas de déficit y endeudamiento del instituto.

Una cuestión relevante en la dinámica de este esquema tiene que ver con la relación entre el sector de obras sociales y el sector privado de prestación de servicios médicos. En todos los casos, la provisión de servicios de las Obras Sociales se realiza 
principalmente a partir de redes de prestadores privados, clínicas, profesionales y farmacéuticas. En este marco, el sistema de obras sociales ha tenido una gran relevancia en el crecimiento del sector privado, con resultados muy diversos de acuerdo al modo de contratación (con o sin gerencias intermediarias, y en caso de contratación directa, con prestadores seleccionados o libre elección del paciente), y al modo de pago por los servicios (por capitas o por prestación constatada de servicio). Esto ha supuesto unas consecuencias muy particulares en la pauta de competencia dentro del mercado, afectando tanto la calidad de los servicios como la utilización de los recursos, en muchos casos orientados a negociados de mayor beneficio para prestadores y funcionarios de obras sociales que para los afiliados.

La competencia en el mercado no se organiza entre demandantes y oferentes de atención médica, sino en torno a la contratación entre financiadores y proveedores. El proveedor que consigue un contrato ha captado una porción de demanda. (...) es una competencia por la obtención de esos contratos, y no se dirime en términos de calidad y precio. Por el contrario, la obtención de contratos está regulada por otras reglas: capacidad de llegada al poder político, antiguas vinculaciones tejidas durante la vigencia del anterior sistema, búsqueda de alianzas más amplias, afinidades de diferente tipo. En ocasiones la firma de un contrato se obtiene a partir del pago de una comisión a los agentes representantes de la entidad financiadora. (Belmartino, 2005: 168)

Esta última cuestión, referida a la vinculación entre las instituciones aseguradoras y el sector privado de prestación de servicios médicos, es una de las principales cuestiones compartidas por PAMI con el resto de las obras sociales. Sin embargo, las particularidades de PAMI como obra social son múltiples: a diferencia de la mayor parte de las obras sociales del país, no está asociada a una rama de actividad en particular y por tanto a un gremio específico; su regulación está a cargo del Ministerio de Desarrollo Social y no de la Superintendencia de Seguros de Salud, y en los hechos ha estado fuertemente asociada al poder ejecutivo, debido a la recurrente historia de intervenciones en el organismo; es la de mayor cobertura y mayor presupuesto, es decir, la más grande obra social del país, y de hecho de toda la región (según el material de prensa analizado); dado que la mayor parte de sus asegurados son personas mayores, el perfil de sus prestaciones está necesariamente atravesado por las necesidades propias de la tercera edad, y por tanto se vincula con un nicho particular del sector privado de prestación de servicios; por otra parte, el financiamiento en este caso no proviene sólo de los ingresos de los propios beneficiarios, sino también de los aportes de los trabajadores en actividad, acentuando la percepción simbólica de constituir un sistema público, al no estar financiado sólo por los propios beneficiarios. Todas estas características han supuesto que PAMI tenga a su vez rasgos propios de las obras sociales y otros propios de sus especificidades y de las dimensiones que la hacen la principal estructura de 
Minoldo. La era menemista del PAMI. Una aproximación al pasado reciente de la obra social de los jubilados en...

seguridad social de la salud en términos de afiliados, de presupuesto y de fuente de contratación de servicios de salud del sector privado.

Comprender el funcionamiento de PAMI, y sus resultados como institución central de la protección de la salud de las personas mayores argentinas, requiere comprender la compleja dinámica que se teje en torno al poder político y económico que algunos actores han disputado en él, así como las diferentes relaciones que se establecieron, probablemente en vinculación con tal disputa, con los prestadores y proveedores, es decir el sector privado de la salud y, durante un largo período, con las intermediarias gerenciadoras.

\section{Antecedentes}

Al buscar información académica de PAMI es posible encontrar menciones en documentos que abordan, por ejemplo, la seguridad social en Argentina, los sistemas de salud en General, el sistema de obras sociales. Sin embargo, las menciones a PAMI en este tipo de material ocupan apenas un par de párrafos, dado que el tema aparece generalmente como marginal al objeto de estudio principal.

Existen otros textos que dedican a PAMI al menos algunas páginas. Uno de ellos, constituye también un informe oficial de PAMI (Espínola, 2005), presentado en una Reunión de Gobiernos y Expertos sobre Envejecimiento de Países de América del Sur. Otro, fue publicado por la oficina anticorrupción (Del Boca \& Rolleri, 2009), y describe las reglas de contratación de servicios de PAMI. Por otra parte, el texto de Ronconi (2002) hace una breve referencia a la recurrente aparición de PAMI en la prensa, relacionado con escándalos de corrupción, entre 1997 y 2001, y dedica una página del anexo a describir algunas características generales del instituto. Un texto de la Comisión Americana de Adultos Mayores (CAAM, 2002) describe algunas características generales de PAMI y proporciona algunos datos estadísticos sobre sus afiliados, recursos y prestaciones. En tanto, Chiara (2002) realiza algunas breves menciones a PAMI con respecto a su vinculación con prestadores sindicales y en el marco de un análisis en conjunto con las obras sociales sindicales. Por otro lado, un documento de la Fundación Atlas (Guido, 2003) dedica dos páginas a exponer algunos datos estadísticos de PAMI en base a documentación oficial. ${ }^{2}$ Lo mismo puede decirse del libro de Gragnolati et al. (2014), el más reciente de los antecedentes.

De los ocho textos encontrados que se ocupan específicamente de PAMI, 3 constituyen publicaciones oficiales del instituto. ${ }^{3}$ En cuanto a los otros, uno de ellos constituye un artículo que analiza la política de medicamentos de PAMI (Melitón et al., 2002). El segundo texto realiza un análisis comparativo entre dos modelos de seguro

2 Los datos expuestos se basan en el documento "Caracterización y evolución del Gasto Público Social, Dirección Nacional de Programación del Gasto Social, Secretaría de Programación Económica, de Junio 1999.

3 Uno es el libro de Víctor Alderete (1999), publicado durante su conducción de PAMI, otro es un texto cuyo prólogo se encuentra firmado por Graciela Ocaña (2007) cuando era la interventora, y otro constituye un informe presentado por PAMI (2012) en un encuentro dedicado al seguimiento de la Declaración de Brasilia, en Costa Rica. 
nacional de salud: el de PAMI en Argentina y Medicare/Medicaid en EEUU (Politi, s/d). Pero los antecedentes verdaderamente relevantes en el estudio de PAMI podrían identificarse en tres trabajos puntuales. Para la década de los 80s existe un completo trabajo de Laura Golbert (1988). Por su parte, Redondo y Rivkin (2002) investigan la satisfacción de los usuarios de PAMI, mediante una encuesta llevada a cabo en 5 localidades argentinas en abril del año 2000 y desarrollan, a continuación, el diseño de un sistema de información centrado en los usuarios para implementar en PAMI. Finalmente, el trabajo de Lloyd-Sherlock (1997) aporta información que no siempre se encuentra claramente respaldada en fuentes, y en otros casos se asienta sobre material de prensa. En tal sentido, dicho trabajo constituye un antecedente relevante de la propuesta de este documento, que se propone un trabajo aún más exhaustivo, rastreando el total de notas periodísticas referidas a PAMI en el periodo de análisis y articulando y describiendo los resultados del modo más completo posible.

Este restringido conjunto de antecedentes requiere ser profundizado para avanzar en el análisis de la obra social más grande del país y de la que depende la salud de la mayor parte de las personas mayores de Argentina. En tal sentido, este trabajo propone hacer un aporte que brinde perspectiva histórica acerca de algunos rasgos de PAMI sobre los cuales la etapa menemista de gobierno dejó una huella profunda.

\section{La etapa menemista desde el relato de la prensa ${ }^{4}$}

\section{La inauguración de un ciclo}

Matilde Menéndez fue el primer nombre propio que la prensa asoció indisolublemente a PAMI como institución corrupta. Durante su gestión como presidenta del directorio del instituto fue denunciada una maniobra de corrupción que involucraba al directorio.

En febrero de 1994 fueron sorprendidos in fraganti ${ }^{5}$ varios prestadores de PAMI de clínicas psiquiátricas en posesión de sobres con presuntas coimas para abonar al presidente de la Asociación de Establecimientos Psiquiátricos de la Argentina, correspondientes al $25 \%$ de lo que tales prestadores recibían como pago de $\mathrm{PAMI}^{6}$ (en concepto de cápitas). ${ }^{7}$

${ }^{4}$ El total de la información expuesta en este apartado se basa en artículos de prensa de los tres periódicos nacionales empleados como fuente. Para no entorpecer la lectura con cientos de referencias, sólo se explicitará el medio del que se obtuvo la información cuando se considere especialmente relevante (por ejemplo, cuando refiera a un análisis particular del autor o proporcione cifras no referidas en otros medios sin haber especificado la fuente).

5 El operativo ocurrió en una sede del Banco de Crédito Argentino.

${ }^{6}$ En una nota de noviembre de 1998, La Nación afirmaba que los detenidos tenían en común su condición de prestadores del PAMI, y cada uno de los sobres encontrados en su poder contenía, exactamente, el veinticinco por ciento de la cápita mensual que cobraron de la obra social de los jubilados y pensionados. Uno de los sobres incluso tenía escrito "Cápita pagada por PAMI, doscientos mil dólares. Monto, cincuenta mil dólares".

7 El sistema de pago por cápitas fue implementado durante la gestión de Matilde Menéndez, sustituyendo el sistema de pago por prestaciones. Supuestamente, para evitar las sobreprestaciones. Consistía en un pago fijo a los prestadores en función de la cantidad de población usuaria potencial, que por un lado daba a PAMI previsibilidad en los gastos pero por otro garantizaba a las empresas el cobro sin importar 
Minoldo. La era menemista del PAMI. Una aproximación al pasado reciente de la obra social de los jubilados en...

Se sospechaba que el pago de las mismas era la condición que aseguraba su continuidad como prestadores. El caso fue bautizado en la prensa como "los retornos del PAMI". Los $\$ 800$ mil secuestrados en el operativo no fueron nunca reclamados.

La Presidenta y su directorio sumaron 32 denuncias penales por diversos delitos que se fueron unificando en diversas causas ante los Juzgados Federales de la Capital, con cargos que iban desde la supuesta contratación de un peluquero personal (con un sueldo de \$5 mil pagados por PAMI), hasta el pago de sobreprecios en la compra de marcapasos, o el uso de dinero del PAMI para realizar ilegalmente préstamos de dinero, en concepto de "adelantos" por servicios médicos, a diversos prestadores. ${ }^{8}$

Menéndez y todo el directorio renunciaron en abril de 1994 asediados por las denuncias, abandonando PAMI con una deuda de \$148 millones, ${ }^{9}$ según informa la prensa. A pesar de las miles de fojas e instancias judiciales que acumuló la causa, la misma terminó sin condenas, luego de pasar por varios jueces que fueron declarándose incompetentes y resolverse en la justicia federal. ${ }^{10}$

Figura 1. Matilde Menéndez

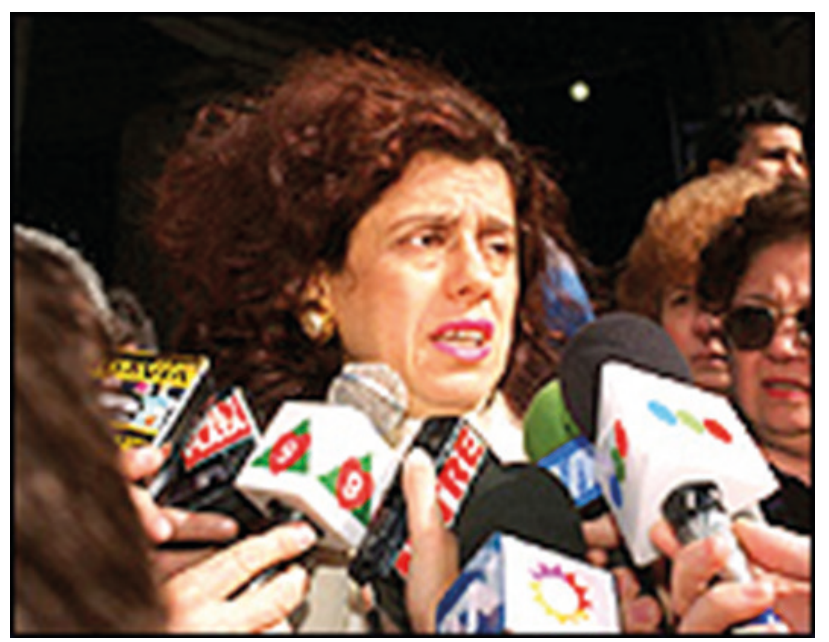

Fuente: Diario Clarín, nota publicada el 5/5/1996.

cuántas prestaciones efectivas realizaran, de modo que sus ganancias serían mayores cuanto menor fuese la calidad y cantidad de prestaciones efectivas.

8 Se sospechaba de 12 operaciones que sumaban entre todas cerca de \$17 millones.

9 Durante el periodo de estudio existía paridad entre la moneda local (peso) y el dólar estadounidense, por lo que los montos a o largo del texto refieren indistintamente a cualquiera de las dos monedas.

${ }^{10}$ Un detalle anecdótico fue la posible extorsión por parte de Menéndez y su abogado a uno de los jueces de la causa, Galeano, amenazado con la difusión de un video que finalmente fue hecho público e incriminaba al juez en el encubrimiento y creación de pruebas falsas en la causa por el atentado en la AMIA. 


\section{Intervenciones sucesivas y años de endeudamiento exponencial}

Luego de la salida de Menéndez y su directorio PAMI fue intervenido por el gobierno. A cargo de la intervención el presidente nombró en el cargo a Carlos Alderete, ${ }^{11}$ ex ministro de Trabajo de Raúl Alfonsín. ${ }^{12}$ En enero del siguiente año, 1995, Carlos Alderete sería reemplazado por Alberto Abad, quien en junio de ese mismo año sería sustituido por Antonio Maldonado. Para entonces el déficit fiscal de PAMI superaba los \$45 millones al mes. El déficit anual de 1995 alcanzaría los \$700 millones (con un presupuesto de $\$ 2400$ millones y erogaciones por $\$ 3100$ millones).

Frente a la falta de recursos para afrontar sus gastos, PAMI demoraba sistemáticamente el pago a los proveedores y prestadores de servicios, aguardando hasta recibir ayuda del Ministerio de Economía. Los prestadores, por su parte, presionaban mediante la suspensión de la prestación de servicios, lo que redundaba en la desprotección de los afiliados.

Aunque la prensa afirma que el $84 \%$ del desequilibrio se explicaba por pagos de prestaciones médicas y solo $6 \%$ por gastos de personal, el gobierno promovía una "racionalización" del instituto. En marzo de 1996 Maldonado declaró que quedarían desafectados a PAMI unos 2500 agentes, que pasarían al Fondo de Reconversión Laboral o a un programa de retiros voluntarios. ${ }^{13}$ Por otro lado, Maldonado afirmó que pretendía licitar las prestaciones para bajar costos sin renunciar a calidad, e incluso mejorándola. De todos modos, no llegó a implementar su programa de ajuste. Con un profundo desgaste en su gestión, ante recurrentes conflictos con los prestadores, frente a la gradualidad y lentitud de la ayuda económica del gobierno, el interventor había dejado en claro que no estaría dispuesto a quedarse en la conducción si PAMI dejaba de recibir el auxilio del gobierno para cubrir el déficit mensual (de entre \$40 y \$45 millones). Finalmente el presidente Menem pidió la renuncia del interventor a fines de julio de 1996. En su reemplazo fue nombrado Alejandro Bramer Markovic quien indicó, en agosto, que la presunta deuda de PAMI (que debía ser auditada) se estimaba en torno a los \$1000 millones. Un decreto de ese mes, el 925/96 (Infoleg, 2018), dispuso

\footnotetext{
${ }^{11}$ Los medios especularon que tal nombramiento se debió a un error y que Menem había querido, en realidad, nombrar a "Víctor" Alderete, y no a "Carlos". Al parecer, un fallo en la comunicación interna hizo que convocaran al Alderete "equivocado" y luego, trascendido su nombre, decidieron no dar marcha atrás para no traslucir la impericia.

12 Años después de su salida de PAMI, en 1998, Carlos sería procesado por una denuncia de Víctor Alderete, debido a una presunta defraudación en la contratación de un servicio de camionetas para dar funciones de cine a los jubilados. La empresa Road Movie habría sido beneficiada de manera abusiva, siendo además que se constituyó comercialmente después que consiguió el contrato con el PAMI. El contrato entre PAMI y Road Movie había sido, de hecho, rescindido por el interventor que sucedió a Carlos, ante las irregularidades detectadas en el mismo, pero por ello la empresa debió ser generosamente indemnizada. Además, fue contratada de manera directa (sin llamado a licitación). También fue procesado, años más tarde, en 2000, por la contratación directa de una empresa (Obrinter SR) para la millonaria remodelación del Hogar Viamonte. Antes del procesamiento, el interventor Maldonado, ordenó en 1995 la instrucción de un sumario administrativo por las "presuntas irregularidades en las obras realizadas".

${ }^{13}$ El plan de reconversión de personal sería respaldado por un crédito (de 200 millones) prometido por el Banco Mundial y ayuda del Ministerio de Economía, que aportaría otros 380 millones para destrabar conflictos con prestadores por demoras en los pagos y licuar el déficit.
} 
Minoldo. La era menemista del PAMI. Una aproximación al pasado reciente de la obra social de los jubilados en...

el relevamiento y control de las deudas y créditos que el PAMI tenía, facultando al interventor a contratar a terceros para realizar las tareas de auditorías.

Figura 2. Autoridades responsables de PAMI y evolución de la deuda del instituto 1994-1999

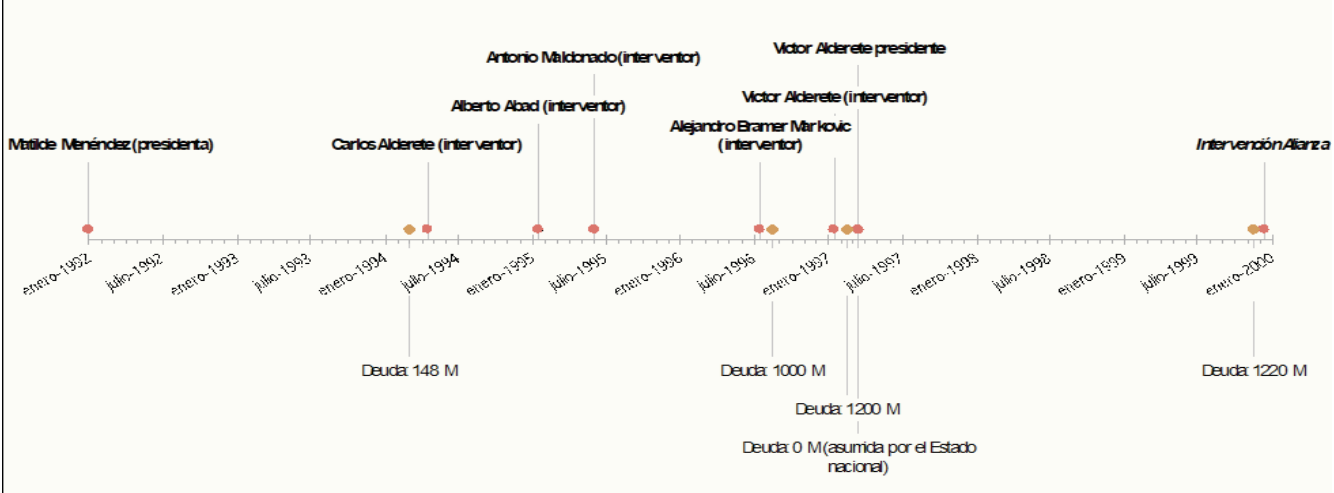

Fuente: Elaboración propia en base a notas de La Nación, Clarín y Página12, entre 1996 y 1999.

\section{Markovic y la reestructuración que no fue}

Marcovick, quien era por entonces el director ejecutivo de ANSES, arribó a PAMI para liderar una reestructuración. El mes en que inició su gestión, el decreto 925/96 dispuso el relevamiento y control de las deudas y créditos. Los acreedores contaban con 60 días para acreditar sus acreencias. El decreto 925 no sólo refería a la deuda de PAMI, sino que además instruía al interventor renegociar y reestructurar todos los contratos en curso y a realizar una revisión integral de la estructura orgánica de PAMI. Se trataba de un plan alineado con las demandas del Banco Mundial. ${ }^{14}$

Figura 3. Alejandro Bramer Markovic

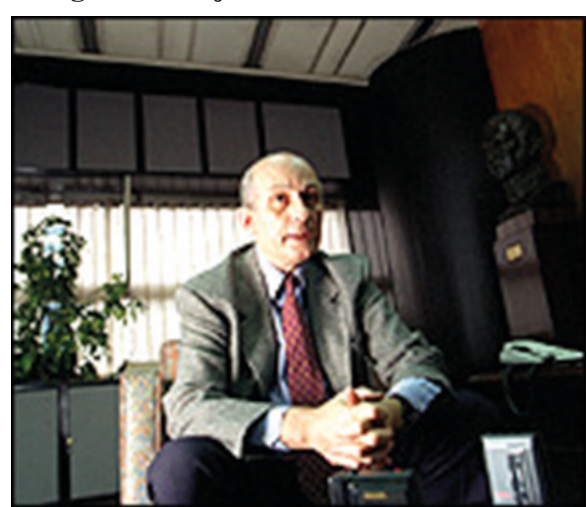

Fuente: Diario Clarín, nota publicada el 4/8/1996.

\footnotetext{
${ }^{14}$ Semanas antes de la asunción de Markovic, el Banco Mundial había otorgado el crédito paliativo para la "reconversión de la obra social" con las exigencias de reducción de personal, renegociación de contratos con prestadores y transferencia de algunos de los programas sociales de PAMI.
} 
Las primeras medidas en este sentido se orientaron a la reducción de personal. Marcovick comenzó despidiendo 50 empleados jerárquicos nombrados por anteriores interventores y 22 delegados (directores de delegaciones regionales). A continuación, anunció una reducción de personal generalizada, evaluado como excesivo que PAMI tuviera 12 mil empleados. ${ }^{15}$ Así, en octubre de 1996 anunció que más de 1800 médicos de cabecera, 1000 trabajadores y asistentes de la red de ambulancias y "varios miles" de empleados administrativos serían dados de baja del PAMI y transferidos al Fondo de Reconversión Laboral para poner "en caja” la obra social. El ajuste no sería suficiente para eliminar el déficit corriente de PAMI, por lo que Markovic elaboró una estrategia que contemplaba "capitar" todos los niveles de atención médica (consulta, internación y tratamientos complejos). De esa manera, se sabrían de antemano todos los gastos. Si bien Markovic reconocía que el sistema de pago por cápitas implicaba el riesgo de que el prestador sub atienda al paciente, señalaba que el sistema de pago por consulta podía llevar a una sobre prestación. Propuso entonces que el equilibrio se obtenga con una férrea auditoria, que se haría con personal de PAMI y contratando consultorías externas. En adición, Markovic anunció que los 6 geriátricos de PAMI serían entregados a terceros y las 18 mil plazas geriátricas solo serían para personas de escasos recursos sin ayuda familiar.

En noviembre de 1996 se anunció una reestructuración más radical, que preveía transferir los afiliados de PAMI a las provincias. Como primer caso, se empezó con un convenio para Buenos Aires con el Ministerio de Salud de la provincia, ${ }^{16}$ para transferir cerca de un millón y medio de jubilados a un nuevo prestador llamado "Consorcio Agrupación Sanitaria, Provincia de Buenos Aires", que era una red de hospitales públicos constituida por el Ministerio de Salud en 1993 y que atendía a 130 mil afiliados del interior. El consorcio podría sub contratar servicios con clínicas y sanatorios privados, que podían ser los actuales prestadores (cuyos contratos caducarían ahora con esta medida), pero por un costo inferior al cobrado hasta ese momento: en lugar de entre $\$ 30$ y $\$ 40$ por afiliado que pagaba a los prestadores privados, PAMI pagaría al consorcio una cápita de $\$ 23,50$. Con este esquema se esperaba que las provincias se encargaran de la atención médica de los jubilados en cada uno de los distritos.

A finales de noviembre la conducción de PAMI fue aún más lejos, anunciando la idea de reemplazar a PAMI por una nueva obra social. La disolución de PAMI permitiría desprenderse de personal y pasar a funcionar con 4 mil personas, mientras 7 mil empleados pasarían al fondo de reconversión. El plan era que el Estado absorbería la deuda de cerca de $\$ 1200$ millones y la pagaría, una vez depurada por auditorias, en bonos. La nueva obra social se encargaría de la atención siguiendo el criterio acordado con la provincia de Buenos Aires, convirtiéndose los ministerios provinciales de salud en aseguradores de la salud a través de los hospitales públicos. La nueva obra social

\footnotetext{
${ }^{15}$ En realidad, una auditoría externa encargada por PAMI informaría, en diciembre de 1996, que la cantidad de empleados era 13700, integrada principalmente por 11.600 empleados y 2000 médicos de cabecera.

${ }^{16}$ Tras la derrota electoral de Duhalde, el 26 de octubre del 97, Alderete cancelaría el acuerdo y PAMI retomaría la atención de esos jubilados.
} 
Minoldo. La era menemista del PAMI. Una aproximación al pasado reciente de la obra social de los jubilados en...

trabajaría con un presupuesto de $\$ 1500$ millones, siendo que en ese momento PAMI no lograba ajustarse al presupuesto de $\$ 2400$ millones.

Mientras tanto, desde el inicio de su gestión, Markovic debió afrontar conflictos con los prestadores y trabajadores que reclamaban el pago de las deudas sin mas demoras ni quitas y/o se oponían a la reconversión de PAMI. Ya a comienzos de septiembre comenzó a producirse un colapso en las prestaciones médicas y asistenciales que brindaba el PAMI. Clínicas y sanatorios privados contratados por PAMI interrumpieron los servicios en reclamo por la falta de pago de hasta 4 meses de prestaciones adeudados. En noviembre de 1996 se produjo otra crisis cuando se intentó imponer una quita de hasta el 60 por ciento en la deuda de más de $\$ 600$ millones de la obra social con los prestadores. ${ }^{17}$ En tanto, las relaciones con los trabajadores de PAMI se tensaron por el anuncio del despido de 6000 trabajadores.

Figura 4. Protesta de trabajadores de PAMI

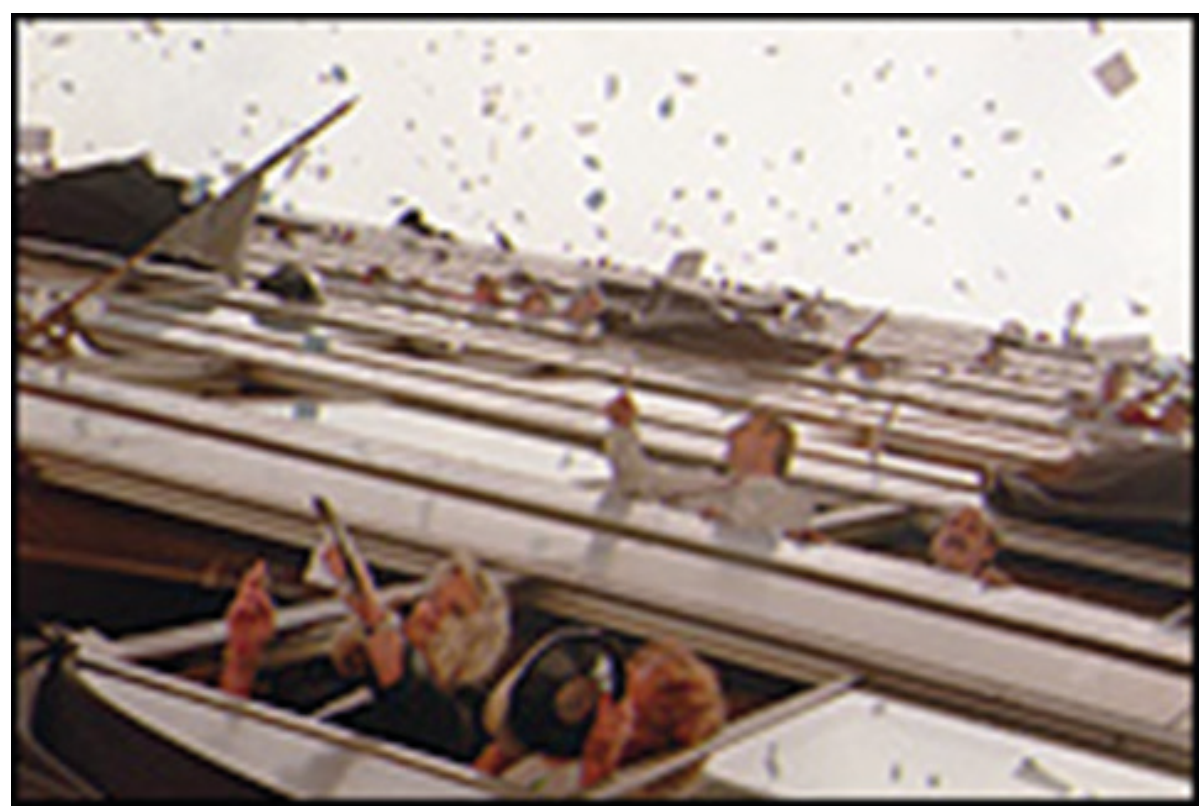

Fuente: Clarín, nota publicada el 22/11/1996.

Por su parte, CGT y CTA reclamaban la normalización del instituto. Agravando los conflictos, el intento de recorte de subsidios alimentarios y de alquiler de PAMI ${ }^{18}$ había generado la resistencia de organizaciones de jubilados. De este modo, se multiplicaban los frentes adversos para el interventor. Cuando parecía que Markovic

\footnotetext{
${ }^{17}$ Las resoluciones 898,906 , y 926/96 ordenaron el reconocimiento de hasta 40 por ciento de las deudas al contado. Los prestadores que desearan cobrar mayor parte de sus acreencias deberían dejar pasar varios años para ir percibiendo el dinero en cuotas.

${ }^{18}$ Markovic quiso reducir a la mitad el subsidio Pro Bienestar, heredado de la gestión de Matilde Menéndez, que insumía \$10 millones de gasto mensual a PAMI, y transferirlo luego a la Secretaría de Desarrollo Social.
} 
sería relevado, logró conservar su puesto dando marcha atrás con el recorte de los subsidios alimentarios y de alquiler. Sin embargo, en el marco de una tensión creciente por la amenaza de interrupción de servicios de los prestadores acreedores de la deuda de PAMI, el gobierno quitó al interventor la autonomía para tomar decisiones, que ahora deberían ser autorizadas por una comisión de funcionarios creada especialmente. ${ }^{19}$ Aún así los conflictos siguieron multiplicándose. A mediados de mes comenzó una huelga nacional de trabajadores de PAMI en contra de los despidos, con la adhesión de las asociaciones Mesa Coordinadora Nacional de Jubilados y Pensionados, así como los Jubilados de Plaza Congreso, mientras la CGT seguía reclamando la normalización del instituto.

A finales de noviembre, cuando se anunció el traspaso de los afiliados a los hospitales provinciales, se produjo un rechazo de diversos sectores a lo que llamaron el "vaciamiento de PAMI", desde prestadores, jubilados y oposición política al gobierno, hasta la iglesia católica. Las sospechas se centraban en que fuese viable proporcionar una atención de calidad con el nuevo esquema, así como en la legitimidad de transferir a los hospitales los recursos "contributivos" recaudados por PAMI. Mientras tanto, las protestas de los prestadores continuaban, reclamando por la deuda cuya quita no aceptaban y tomaron medidas de fuerza en los últimos días de noviembre. La relación entre la intervención de PAMI y los prestadores se tensó fuertemente y a mediados de diciembre se tomaron medidas de fuerza conjunta por parte de dueños de clínicas y empleados, reclamando en simultáneo el pago de la deuda, la defensa de fuentes laborales y la normalización de PAMI (es decir, el fin de la intervención). Los reclamos se sumaron a la protesta contra la desregulación generalizada de las obras sociales. El interventor, por su parte, respondía acusando a las prestadoras por la mala calidad y sobrefacturación de los servicios de PAMI.

En tanto, el informe de octubre de 1996 de la Auditoría General de la Nación (AGN) había identificado sobreprecios a clínicas y sanatorios con un exceso en torno a \$200 millones, que explicaba entre el 30\% y 50\% del rojo anual de PAMI. Además, se identificó una baja calidad prestacional. Pero en diciembre de 1996 la imagen de PAMI se deterioró aún más cuando se conoció el informe de una auditoria externa encargada por el organismo, que sacó a la luz un enorme fraude vinculado con el sistema de ambulancias, con una sobrefacturación que ascendía al 40\% e involucraba una suma de 25 millones al año. ${ }^{20}$

${ }^{19}$ La comisión estaba encabezada por el ex titular de esa obra social y actual secretario de Control Estratégico de la Jefatura de Gabinete, Alberto Abad, e integrada por varios ministros.

${ }^{20}$ Markovic hizo realizó presentación judicial por el caso. El sistema de ambulancias vigente había sido implementado en 1993 por Matilde Menéndez, quien ideó un sistema de ambulancias con unidades propias y contratadas. Según el informe, en muchos casos, las ambulancias contratadas pagaban una "coima" que, según voceros del PAMI, era del 10 por ciento. Además, se verificó que las ambulancias propias del PAMI habían sido utilizadas por empresas privadas. En algunos casos, se habían pagado traslados de alta complejidad en casos innecesarios, como por ejemplo por un dolor de muelas. Para la sobrefacturación se detectó una maniobra que los fiscales bautizaron como "Diez por Uno": las firmas le facturaban al PAMI diez traslados diferentes con tarifas individuales, pero realizaban traslados colectivos. Así, por ejemplo, un jubilado que tenía que hacerse una diálisis a las 10 de la mañana era retirado de su casa a las 6 . 
Minoldo. La era menemista del PAMI. Una aproximación al pasado reciente de la obra social de los jubilados en...

Hacia fines de diciembre, en una aparente estrategia para desligarse de las responsabilidades por la circunstancia del instituto, el propio interventor presentó una denuncia en la justicia en la que denominó un "descalabro" la situación de PAMI, señalando la existencia de "maniobras millonarias" y el peligro que corría la salud de muchos jubilados. Denunció casos de internaciones innecesarias, incluso en institutos neuropsiquiátricos, para facturar prestaciones; casos de cobro de servicios extra, por parte de los prestadores, para brindar prestaciones que en realidad contaban con plena cobertura; medicamentos que eran entregados a jubilados luego de haber sido devueltos. También denunció sobrefacturación de una misma prestación, falta de depuración del padrón de afiliados (con afiliados "truchos", que llevaban a sobredimensionar los pagos por "cápitas"), procedimientos poco transparentes en el área de compras y ausentismo excesivo de los empleados, entre otros problemas del uso de recursos del organismo. De este modo, el interventor puso la responsabilidad de los problemas de PAMI en aquellos que protagonizaban su oposición, y la transfirió al área de la justicia. Las denuncias generaron aún más malestar en todos los frentes de oposición a la intervención. En un escenario de alta conflictividad social y política para con la intervención, con la pérdida del apoyo del gobierno, la estrategia de cubrir sus espaldas presentando una denuncia penal terminó de deteriorar las relaciones Bramer Markovic con sus superiores. Finalmente, a mediados de enero de 1997 fuese sustituido por un nuevo interventor: Víctor Alderete, amigo del presidente con experiencia en el ámbito de la medicina prepaga.

\section{La llegada de Víctor Alderete, normalización y rescate estatal de PAMI (1997)}

Víctor Alderete cerraría el ciclo menemista, primero como interventor y luego como presidente del directorio, permaneciendo en PAMI hasta el cambio de gobierno que lo desplazaría por medio de una nueva intervención.

La gestión de Alderete comenzó desactivando frentes de protesta, anunciando no tener prevista una política de despidos y desmarcándose de los proyectos de la anterior intervención, aclarando que no estaba ligado a lo que haya acontecido ni venía a "analizar el pasado de PAMI". Asimismo, llegó con la promesa de una pronta normalización del instituto.

En un año electoral, el gobierno se mostró dispuesto a respaldar económicamente la nueva intervención de PAMI. En febrero el interventor anunció que el Estado se haría cargo de pagar la deuda, ${ }^{21}$ que ascendía ya a más de $\$ 1200$ millones, de modo que la normalización del instituto se produciría "con un equilibrio económico de base cero". También anunció que desde ese mes se restablecería el flujo de pago a los prestadores. Sin embargo, el déficit mensual del organismo seguía rondando los $\$ 60$ millones. Al momento de la normalización en marzo, Alderete anunció que PAMI tendría asegurada la cobertura del déficit mensual hasta diciembre de ese año, con fondos del Estado y del Banco Mundial. En ese plazo, el déficit debía ser eliminado mediante la reconversión de PAMI, que sería monitoreada por el Banco Mundial.

${ }^{21}$ La deuda quedaría a cargo del Ministerio de Economía. 
A diferencia de la modalidad de confrontación de Bramer Markovic, Alderete anunció la intención de diálogo con los diferentes actores. Con relación al conflicto por el decreto que disponía una fuerte quita en las deudas de PAMI, anunció que el Gobierno estaba instrumentado "medidas económico-financieras ciertas y serias".

En febrero declaró que se aplicaría un sistema de "reconversión laboral" para reducir la "excesiva dotación" de personal de PAMI y su peso sobre el déficit mensual del organismo. Sin embargo afirmó que no se trataba de una política de despidos. ${ }^{22}$ Por un lado, propuso un sistema de retiro voluntario y por otro sugirió la idea de depurar el organismo de personas que no cumplían verdaderamente funciones. En marzo anunciaría que, al momento de la normalización, habría logrado reducir 2800 empleados del personal de 13700 empleados, mediante el (atractivo) plan de retiros voluntarios aplicado durante su corta gestión. ${ }^{23}$

En marzo de 1997 se firmó finalmente, con el decreto 197/97, la normalización de PAMI a partir del 12 de marzo de ese año y la transferencia al Estado de las deudas del organismo impagas hasta el 31 de diciembre de 1997. Es decir, las existentes y las que se contrajeran a lo largo del año.

El decreto afirmaba que estaban dadas las condiciones para la normalización, aunque en los hechos el instituto normalizado heredaba los mismos problemas que habían justificado las sucesivas intervenciones. Alderete fue designado por el gobierno como presidente del directorio, continuando así en la conducción de PAMI, junto con 12 delegados. ${ }^{24}$

A mediados de abril Alderete anunció la presentación de 15 demandas penales contra prestadores y particulares, a quienes evitó identificar en sus anuncios con la prensa, involucrados en maniobras fraudulentas. ${ }^{25}$ Asimismo, el titular de la obra social anunció que PAMI tenía sus deudas al día, habiendo pagado las prestaciones de marzo.

En mayo PAMI alcanzó un acuerdo con los laboratorios para que éstos se encargaran de la distribución de productos farmacéuticos, lo que ampliaría la variedad de medicamentos accesibles para afiliados de PAMI, en algunos casos con cobertura de hasta el $100 \%$, garantizaría la provisión con más seguridad y permitiría, además, un

\footnotetext{
${ }^{22}$ Las buenas relaciones del interventor con los empleados tuvieron sus primeros roces cuando, a mediados de febrero, Alderete sacó a 1225 empleados de PAMI los adicionales por función que venían cobrando hacía varios años (el ahorro estimado con la medida era de \$1 millón y medio por mes). Además, el interventor anuló más de 150 contratos de trabajo (el ahorro estimado en este caso alcanzaba $\$ 300$ mil por mes). Los empleados perjudicados respondieron denunciando al interventor por diversas razones, como haber nombrado a familiares en cargos del instituto (a lo que Alderete respondió que trabajaban Ad Honorem).

${ }^{23}$ En diario La Nación, Ricardo Chamorro estimaba que los 3000 retiros voluntarios conseguidos hasta fines de marzo implicaban un gasto de cerca de $\$ 50$ millones, aunque el cálculo resulta confuso cuando luego afirman que los retiros promediaban los $\$ 50$ mil por persona (lo que resultaría en $\$ 150$ millones).

${ }^{24}$ Los miembros del directorio percibían un ingreso de $\$ 9$ mil entre asignación fija, viáticos y pago por desarraigo, cuestión que tuvo repercusiones en la prensa cuando la información se conoció a comienzos de abril.

${ }^{25}$ Las denuncias referían a fraudes de compras de medicamentos con descuento de PAMI por parte de geriátricos, la híper prescripción de medicamentos, casos de mala praxis, médicos de cabecera que continuaron cobrando salario hasta un año después de haber quedado desvinculados, y también casos de coimas cobradas por falsos gestores, que prometían facilitar el cobro de las deudas de PAMI.
} 
Minoldo. La era menemista del PAMI. Una aproximación al pasado reciente de la obra social de los jubilados en...

ahorro para PAMI de entre $\$ 50$ y $\$ 75$ millones anuales. En julio, PAMI logró que se restablecieran en Capital las prestaciones de sepelio que se habían suspendido desde enero por falta de pago de una deuda que ascendía a $\$ 13$ millones, tras un acuerdo que incluía efectivizar el pago de una parte de la deuda (abonando \$900 mil).

En julio, la fluidez con la que PAMI recibía ayudas económicas del gobierno comenzó a verse resentida, trascendiendo fricciones entre el titular de PAMI y el ministro de economía, Roque Fernández. El ministro puso como condición, para girar los fondos, que la Sindicatura General de la Nación (SIGEN) confirmara la que los reclamos fuesen adecuados luego de revisar los expedientes. Ante los reclamos de Alderete, el ministerio le reprochó la falta de avances en la reducción del déficit de PAMI, instando a que se avanzara en un programa de ajuste y se redujera la carga de PAMI sobre las cuentas del gobierno. La discusión se saldó con un decreto del presidente que autorizó la reasignación de partidas presupuestarias para el funcionamiento del PAMI, evitando una crisis en plenos tiempos electorales.

\section{Las gerenciadoras en la mira de la oposición política (1998)}

La oposición a la conducción de Alderete tuvo su primer episodio relevante en agosto de 1997, cuando un grupo de legisladores opositores junto al ombudsman de la tercera edad, Eugenio Semino, pidieron la renuncia del presidente de la obra social, Víctor Alderete, y del directorio por considerar que existían una serie de "irregularidades" en el manejo del organismo. ${ }^{26}$ Alderete los acusó de defender los intereses de prestadores con cuyo reemplazo fue posible un ahorro para PAMI.

En febrero de 1998, finalmente, un grupo de legisladores opositores presentó una denuncia contra el presidente del PAMI por "violación de los deberes de funcionario público" y "malversación de los caudales del Estado". El nudo de las denuncias se vinculaba con el sistema de intermediación creado por el cual PAMI no contrataba los prestadores sino a empresas gerenciadoras que se encargaban de proveer las prestaciones, subcontratando prestadores de servicios, y reteniendo ganancias sin topes regulados. Además, las empresas gerenciadoras eran contratadas sin licitación previa, a pesar de tratarse en muchos casos de empresas desconocidas, sin antecedentes. ${ }^{27}$ Los

\footnotetext{
${ }^{26}$ Entre los cuestionamientos, se encontraba el convenio que el PAMI firmó con los laboratorios para la provisión de medicamentos, en forma directa y sin licitación previa, con una duración de 5 años. Además criticaban los convenios con los institutos de atención psiquiátrica que suscribió PAMI con Facap, involucrada en el escándalo de los "retornos" en tiempos de Matilde Menéndez. También denunciaban que la capacitación del personal presentaba supuestas irregularidades que involucran grandes sumas de dinero.

${ }^{27}$ En las denuncias se incluían los 20 contratos directos de servicios médicos que había firmado Alderete en el último semestre de 1997. Uno de los "casos testigos" que la oposición eligió para demostrar la existencia de un mecanismo presuntamente fraudulento en la administración de los recursos del organismo fue el de la firma Funeral Home SA, que realizaba el gerenciamiento de los sepelios de los afiliados al sistema. El segundo "caso testigo" refería al contrato con la empresa cordobesa Cobertura Federal de Salud (Cofesa) para la atención de 30.000 ex combatientes de la Guerra de las Malvinas. Los denunciantes afirmaban que PAMI se había comprometido a abonar a Cofesa $\$ 25$ por cada afiliado veterano con un familiar a su cargo mientras que la empresa intermediaria, a su vez, habría contratado el servicio asistencial por $\$ 13,50$ por cabeza. A fines de marzo los legisladores sumaron denuncias por los
} 
denunciantes estimaban que el dinero perdido por la intermediación de estas empresas rondaba entre los \$200 y \$300 millones anuales. Al tener en cuenta esto, sumado al ajuste de las cápitas abonadas, lo que efectivamente se pagaba por prestaciones médicas se reducía considerablemente, pudiendo afectar la calidad de los servicios.

Alderete defendió el sistema por gerenciamiento con intermediarias y afirmó que cuando PAMI se ocupaba directamente de contratar a los prestadores se gastaba más dinero y se administraban mal los fondos. Según afirmaba, los resultados quedaban en evidencia por las mejoras en las cuentas de PAMI, cuyo déficit se había reducido, según él, de \$60 a \$5 millones mensuales. Consideró adecuado que las las gerenciadoras cobraran por su trabajo y apuntó que no correspondía regular topes en las comisiones de las intermediarias ya que se trataba de contratos en los que las empresas asumían el riesgo. Asimismo, defendió la contratación directa puesto que PAMI, al no ser propiamente un organismo público, no estaba obligado legalmente a realizar licitaciones públicas que, insistía, no habían garantizado la transparencia en el pasado.

\section{La opacidad de PAMI}

Aunque Alderete insistía constantemente en el equilibrio de las cuentas de PAMI, lo cierto es que existían diversas dudas respecto a la realidad de las cuentas que Alderete evitaba sistemáticamente someter a la Auditoría General de la Nación (AGN). Por otro lado, el informe de la auditoría de junio de 1997 (firmada por Perversi) no fue hecho público y fuentes anónimas aseguraban que el informe era "lapidario y alarmante" y que Perversi había sido amenazado para que no hablara.

Por otra parte, Alderete aseguraba que el balance de 1997, monitoreado por el Banco Mundial, demostraba el equilibrio financiero de PAMI. Sin embargo, cuando dicho balance se hizo público en abril de 1998, se conoció que, a finales de octubre de 1997, el déficit de PAMI ascendía a casi \$278 millones. Al observar los gastos desagregados se apreciaban recortes en las prestaciones sociales, y una expansión de gastos administrativos a medida que se acercaban las elecciones legislativas. ${ }^{28}$ Por su

pagos que PAMI realizaba a la empresa Lutz Ferrando y a la Organización Federal de Prestación Óptica Integral, muy superiores al costo real de los productos provistos y con una ganancia "injustificada" y "exagerada" para la intermediaria.

Otra de las denuncias apuntó a la Federación de Asociaciones y Cámaras de Establecimientos Geriátricos de la República Argentina (Fegera), que se quedaría con el 50\% de lo que le paga el PAMI, subcontratando las instituciones geriátricas por la mitad de lo abonado por el instituto. Por otra parte, desde junio de 1997 (cuando se firmó el contrato), la intermediaria habría recibido dineros extras de la obra social para instalarse, porque antes del contrato prácticamente no existía como empresa. Así, los pagos habrían estado sobredimensionados y fueron aminorando hasta llegar al monto real que precisaba la intermediaria para subcontratar prestadores. Cuando Alderete concurrió al Congreso a dar explicaciones, explicó que se abonaba así para que se fuera montando la intermediaria. En octubre ingresaría también una denuncia por la firma del convenio con un servicio de miniturismo que ataba a PAMI con el prestador hasta 2003 y que le costaría mensualmente 1 millón 300 mil, considerado excesivo por los denunciantes, para organizar las excursiones con los jubilados a lugares gratuitos, como museos, ferias artesanales, el parque Tres de Febrero, la Reserva Ecológica y Puerto Madero.

28 Uno de los detalles más curiosos era el gasto en el ítem "otros costos de funcionamiento" que 
Minoldo. La era menemista del PAMI. Una aproximación al pasado reciente de la obra social de los jubilados en...

parte, los gastos de publicidad ascendían en todo el año a $\$ 7$ millones y en septiembre se concentraba un gasto de \$3 millones, mientras que en 1996 el gasto en ese ítem había sido de menos de $\$ 6500$.

Otro cuestionamiento a la gestión de Alderete, referido a la falta de controles, señalaba que los contratos suscriptos con las empresas intermediarias no superaban en ningún caso las tres carillas y ninguno dedicaba más de un par de párrafos al tema de controles y auditorías. En algunos contratos, el PAMI requería que la empresa se auditara a si misma. ${ }^{29} \mathrm{Al}$ respecto, Alderete sostenía que los contratos largos no garantizaban mayor eficiencia y que el hecho de que no figuraran controles por parte de PAMI no implicaba que éste dejara de tener atribución para hacerlos. De hecho, aseguraba que PAMI estaba haciendo más auditorías que nunca.

También se sospechaba que Alderete “cajoneaba" (silenciaba o escondía) denuncias. ${ }^{30}$ También, se le acusaba de seguir contratando empresas denunciadas por enormes estafas a PAMI. Alderete respondía que las empresas no eran dadas de baja porque eran las "preferidas" de los jubilados, y que a la "gente grande" le costaban los cambios. Fuentes vinculadas con las investigaciones aseguraban que en las denuncias del PAMI había elementos de sobra para suspender las prestaciones por violación de contrato y frenar los pagos hasta que se determinara la dimensión del fraude cometido. Sin embargo, Alderete alegaba no haber recibido ninguna orden judicial de desvincular estas empresas o de dejar de pagarles por sus servicios. Para otros casos alegaba que no era PAMI quien las contrataba, sino las gerenciadoras, ${ }^{31}$ y que eran éstas las que debían rendir cuentas a PAMI.

\section{El plan de "privatización" y la pulseada judicial}

A mediados de junio de 1998, Alderete anunció el plan de fortalecimiento institucional, que implicaba un cambio en la forma de contratación de las empresas

ascendía a \$30 millones, mientras el año previo Markovic había gastado \$2 millones en ese rubro.

${ }^{29}$ Por ejemplo, en el contrato el suscripto con la empresa gerenciadora de ambulancias Cruz Alsina, siendo que PAMI había denunciado el año previo a varias empresas que ahora integraban la red de Cruz Alsina por estafas reiteradas a la obra social.

${ }^{30}$ El fiscal Sáenz, que lideraba un equipo de fiscales destinados a investigar las denuncias hechas por Bramer Markovic, se enteró en abril de 1998 que, antes de irse, el equipo de Bramer había preparado una ampliación de denuncia en contra de siete empresas fúnebres, entre ellas Cochería Paraná. Sáenz entregó un escrito en el PAMI solicitando que le remitiera el proyecto de denuncia preparado por Bramer Markovic. A las 24 horas, Alderete presentó en el juzgado de Urso una denuncia en contra de las empresas fúnebres, idéntica al proyecto armado por el equipo de Bramer. La presentación acusaba a las empresas fúnebres de cobrar por servicios incluidos en la cobertura del PAMI, haciéndoles creer a los familiares del deudo que dichos gastos serían reintegrados por el PAMI. Las empresas también les hacían creer erróneamente a los familiares que el servicio no incluía impuestos, coche de acompañamiento o sala velatoria, y se los cobraban como gasto adicional. Se mencionaban casos en que las empresas mostraban a un familiar del fallecido un ataúd de cartón y le decían que era el que les proveía el PAMI. Después le pedían más dinero para el ataúd de madera que debían entregar gratis de acuerdo con el contrato del PAMI.

31 Algunas de las gerenciadoras habían sido denunciadas porque, aunque no tenían inconvenientes en contratar a prestadores denunciados, excluían arbitrariamente el ingreso a otros prestadores, que denunciaban haberse negado a pagar coimas. 
gerenciadoras, que consistiría en una selección por concurso de las gerenciadoras prestacionales y permitiría a los jubilados elegir entre no menos de dos empresas de ese tipo por año. Para implementarlo, sería abierto un registro donde constarían las firmas interesadas que competirían libremente entre sí. Sin embargo, la implementación del plan pasó a un segundo plano al abrirse en junio un crítico frente de conflicto por el paro de anestesistas en Capital Federal y el Gran Buenos Aires, que duró 40 días (ver más adelante). A mediados de septiembre Alderete volvió a impulsar el Plan de Fortalecimiento Institucional, llamando a concurso para formar redes nacionales de prestadores $^{32}$ que operarían durante los siguientes cinco años. El nuevo sistema se pondría en marcha a partir de febrero de 1999.

La oposición se opuso fuertemente al proyecto que condicionaba el sistema por 5 años e incluía una cláusula el los contratos por la cual, en caso de rescisión, PAMI debería abonar dos meses de cápitas. ${ }^{33}$

En octubre se abrió un nuevo frente de conflicto que llevó a la suspensión de los descuentos en medicamentos a los afiliados del PAMI (ver más adelante). En medio de la crisis, los planes anunciados quedaron al margen. Apenas destrabado el conflicto con las farmacéuticas, a fines de octubre los gobernadores justicialistas desataron una puja política por manejar los fondos del PAMI, pidiendo "federalizar o provincializar" la obra social y solicitando que se suspenda la creación de las redes nacionales de salud. ${ }^{34}$ Finalmente, tras una reunión con 21 gobernadores y ministros provinciales Alderete anunció la suspensión por 20 días del llamado a concurso para crear redes nacionales de salud. Sin embargo, inmediatamente luego de dicha reunión, los reclamos de provincialización de PAMI perdieron fuerza y los mandatarios declararon que realmente no habían reclamado la federalización de PAMI ni la transferencia de presupuesto a las provincias, sino que había sido un malentendido. Sólo querían asegurarse que los hospitales provinciales no quedaran excluidos en el nuevo plan. De este modo, luego del plazo concedido, el plan para crear redes nacionales de prestadores seguiría su marcha.

El 15 de enero de 1999, una jueza en lo Contencioso Administrativo ordenó suspender el proceso de contratación de las redes médicas privadas que el PAMI tenía previsto adjudicar el 22, haciendo lugar a un recurso de amparo presentado por la defensora del Pueblo de la Ciudad de Buenos Aires, Alicia Oliveira. Oliveira había presentado una acción de amparo hasta tanto se determinara la legalidad y conveniencia del concurso. Para Oliveira las bases de la selección establecidas por el PAMI contenían

\footnotetext{
${ }^{32}$ Las nuevas redes de salud se harían cargo de los servicios de médicos de cabecera, internación de baja, media y alta complejidad, mientras que las prestaciones como psiquiatría, trasplantes, provisión de anteojos, prótesis y sepelios mantendrían el régimen vigente de contrataciones directas.

${ }^{33}$ En las bases originales del concurso, si el PAMI rescindía el contrato a las empresas ganadoras, estaba obligado un mes de capitas por cada año no trabajado -un total máximo de $\$ 450$ millones -. En enero el directorio del PAMI hizo algunas modificaciones, disponiendo pagar hasta un máximo de dos cápitas por contrato anulado, es decir, unos $\$ 180$ millones.

${ }^{34}$ Los gobernadores alegaban que las deficiencias de atención de PAMI eran cubiertas por los hospitales públicos provinciales, generando erogaciones extras. En noviembre un grupo de senadores oficialistas se sumó al pedido de descentralizar PAMI a niveles provinciales. Asimismo, solicitaron la renuncia de Alderete y la suspensión del concurso de redes nacionales de salud.
} 
Minoldo. La era menemista del PAMI. Una aproximación al pasado reciente de la obra social de los jubilados en...

un extenso enunciado de irregularidades, omisiones y faltas de transparencia ${ }^{35}$ y consistía en los hechos en una virtual privatización de la principal obra social del país, con probables consecuencias económicas devastadoras. El PAMI apeló y a los pocos días la jueza desestimó su fallo anterior y autorizó al PAMI a proseguir con la licitación. ${ }^{36}$ Así, el 29 de enero, luego de conocerse una resolución de la jueza, PAMI se dispuso a avanzar en la licitación de los servicios médicos. Como resultado de la licitación, tres grupos $^{37}$ se quedaron con el negocio de las redes de prestadores y los jubilados deberían optar por uno de ellos. ${ }^{38}$

En medio de un clima caldeado por protestas de los médicos de cabecera en contra de las licitaciones, ${ }^{39}$ el 11 de febrero la Justicia volvió a frenar la privatización del PAMI. La Defensora Oliveira había apelado el fallo que autorizó al PAMI a proseguir con la licitación y la Cámara Nacional Federal de la Capital Federal dispuso revocar dicho fallo, ordenando suspender la "privatización". ${ }^{40}$ Cuando Alderete anunció que no acataría el fallo y seguiría adelante, la Cámara en lo Contencioso le prohibió a Alderete continuar con el plan y aclaró que, de persistir, incurriría en delito. El 19 de febrero, la Sala IV de la Cámara en lo Contencioso Administrativo Federal rechazó el pedido de la obra social de levantar la suspensión. A su vez, el 20 de febrero, un juez federal en lo contencioso administrativo ordenó también suspender los planes de las nuevas prestaciones médicas, al aprobar una medida cautelar solicitada por diputados nacionales de la Alianza-Frepaso

A fines de abril el expediente de la causa iniciada por Oliveira llegó a la Corte Suprema. Oliveira recusó a siete integrantes de la Corte Suprema de Justicia,

${ }^{35}$ Según La Nación (14/01/1999), Oliveira se basó en un informe preparado por la Fundación Argentina para el Desarrollo con Equidad.

${ }^{36}$ Alderete aseguró que pediría un "resarcimiento económico" a Oliveira de \$6 millones, ya que la suspensión había provocado "30 días de atraso" en los planes originales y el PAMI tenía según él un déficit diario de $\$ 200$ mil.

${ }^{37}$ Siglo XXI, Argentina Salud y Plan Azul.

${ }^{38}$ Una vez afiliado, el beneficiario pasaría a ser atendido por los prestadores de su red. Las redes se encargarán de la atención primaria, especialidades, internaciones y tratamientos de alta complejidad, a través de médicos de cabecera. También de los estudios de laboratorios. El PAMI le pagaría a cada grupo o red $\$ 21$ por mes por cada beneficiario (cápita), lo que representa $\$ 84$ millones por mes o unos $\$ 1000$ millones por cada año. Las redes deberán destinar por lo menos $85 \%$ de sus ingresos a la prestación médica. El resto era para cubrir los costos administrativos y la rentabilidad, que no podría ser superior al 5 o 6\%. En consecuencia, el costo directo de la atención médica y servicios de laboratorio quedaba reducido a $\$ 17,85$ mensuales por cada jubilado.

${ }^{39}$ El 2 de febrero comenzó una huelga de médicos de cabecera para protestar por las licitaciones. Los médicos que realizaban el paro alegaban que además muchos de ellos no cobraban sus salarios desde octubre del año anterior. El gremialista Almada explicó que el pedido abarca los sueldos atrasados "en dos o tres meses" de unos 1500 médicos de las gerenciadoras y de otros 500 del PAMI. Por otra parte, a partir de abril, cuando comenzara el nuevo sistema, los médicos tendrían un cupo cero de pacientes, es decir que habrían perdido a sus pacientes históricos. En tanto, Alderete decía que los sueldos de los médicos estaban al día y minimizaba el acatamiento de la huelga.

${ }^{40} \mathrm{El}$ presidente Menem, quien en todo momento apoyaba a Alderete, sostuvo que la sentencia "podría ser admisible en la época del nazismo en Alemania, pero no aquí, en la República Argentina donde vivimos en libertad, en democracia". 
alegando un "temor fundado" de que los magistrados carezcan de "imparcialidad y de independencia". 5 meses más tarde, a comienzos de octubre la Procuración General de la Nación elevó su informe a la Corte recomendando que la Justicia debería "dejar sin efecto" el fallo que congeló la puesta en marcha de las tres redes de salud que ganaron el concurso. ${ }^{41}$ A mediados de octubre había expectativas de que los jueces de la Corte levantaran la suspensión antes del cambio de gobierno (que sería en diciembre). Sin embargo, el 22 de octubre, una nueva denuncia penal ${ }^{42}$ entorpeció nuevamente la autorización de las redes, al acusar a las empresas ganadoras del "delito de falsificación (de documentación) en forma reiterada”. ${ }^{43}$ Aún así, el 6 de diciembre, pocos días antes del cambio de gobierno, circulaba el rumor de que la Corte estaba a punto de firmar un fallo que dejaría sin efecto la suspensión dictada por la Sala IV de la Cámara en lo Contencioso Administrativo Federal. Ante ello, el presidente electo (que asumiría el 10 de diciembre) declaró a la prensa que una medida semejante sería un "gesto innecesario" que podría afectar "las relaciones con el próximo gobierno". A su vez, las propias empresas adjudicatarias hicieron declaraciones a la prensa que dejaban entrever la pérdida de interés en reflotar las redes. Quedaba también pendiente la impugnación de una de las empresas que participó en la licitación y no fue seleccionada había presentado (AMI SA) y la posibilidad de una nueva impugnación debido a que, en la medida que los hospitales públicos de la ciudad de Buenos Aires decidieron no integrar las redes ganadoras, la oferta que inicialmente presentaron las empresas se modificó. La Corte no emitió ningún fallo esos días y el 17 de diciembre, con el nuevo gobierno y el PAMI ya intervenido, la nueva conducción de PAMI presentó un recurso para desistir del recurso extraordinario interpuesto por Alderete. Finalmente, el 24 de diciembre la Corte Suprema de Justicia dejó sin efecto el proceso de adjudicación del sistema de salud, al dar lugar al pedido que presentaron los interventores en la obra social.

\section{EI descalabro contable de PAMI y las crisis de prestaciones}

Los últimos dos años de gestión de PAMI se caracterizaron no sólo por las contiendas judiciales y las denuncias reiteradas de parte del partido opositor (la Alianza) sino también por conflictos con los prestadores de servicios que, frente al retraso de los pagos, tomaron medidas de fuerza que suspendieron recurrentemente las prestaciones de salud para los afiliados. A su vez, las crisis prestacionales se vinculaban fuertemente con el déficit estructural de PAMI y las pujas de recursos entre PAMI y el Ministerio de Economía, ante las constantes demandas de PAMI para recibir ayuda económica.

En junio de 1998 se produjo una profunda crisis de las prestaciones de PAMI cuando la Asociación de Anestesiología dispuso un cese de actividades que afectó las cirugías en Capital Federal y el Gran Buenos Aires. Reclamaban el pago de la deuda

\footnotetext{
${ }^{41}$ El dictamen de Felipe Daniel Obarrio, de la Procuración General de la Nación, consideró “arbitraria” la sentencia de los tres camaristas que suspendieron el plan.

${ }^{42}$ Que formuló el diputado nacional Federico Soñez (Alianza), en Paraná.

${ }^{43}$ La denuncia aseguraba que entre los listados de médicos que presentaron las empresas ganadoras para Entre Ríos habría profesionales inexistentes, falsos o que nunca dieron su consentimiento.
} 
Minoldo. La era menemista del PAMI. Una aproximación al pasado reciente de la obra social de los jubilados en...

que PAMI mantenía desde hacía un año y que se aplicara nuevamente el sistema de contratación directa sin intermediarias. ${ }^{44}$ Luego de 40 días de paro, se obtuvo acuerdo entre PAMI y anestesistas, al acordarse un plan de pago de la deuda en el que la obra social se comprometió a actuar como garante del pago de las sumas que las intermediarias debían a los profesionales. El conflicto con los anestesistas puso en el debate público el cuestionamiento por la capacidad del nuevo sistema con gerenciadoras para asegurar las prestaciones. Los conflictos por la demora o falta de atención a los jubilados comenzaron a multiplicarse. El 17 de julio las organizaciones de tercera edad ya habían denunciado al menos tres casos de muertes por demoras del PAMI en la asistencia a jubilados.

El insistente discurso acerca del equilibrio financiero de PAMI empezó a dar paso, en agosto de 1998, al reconocimiento de dificultades económicas. En ese mes, un decreto presidencial autorizó a PAMI a pedir un crédito en el mercado local o internacional, de entre $\$ 500$ y $\$ 600$ millones de dólares. ${ }^{45}$ Si bien finalmente no encontraría quién le otorgara el préstamo, en aquella oportunidad Alderete reconocería que la falta de pagos de la obra social había puesto al sistema nacional de salud "al borde de la asfixia".

En octubre de 1998 la gerencia financiera de PAMI reconoció deudas corrientes del instituto por $\$ 210$ millones, correspondientes a las prestaciones otorgadas en setiembre, con una caja "en cero". Ese mes, la Confederación Farmacéutica Argentina (CFA) decidió suspender los descuentos en medicamentos a los afiliados del PAMI hasta que PAMI regularizara su deuda. Finalmente, el conflicto se destrabó transitoriamente con el pago de un adelanto de la deuda, financiado por el Banco Nación. ${ }^{46}$

Desde octubre de 1998 se hizo pública una disputa entre la conducción de PAMI y el Ministerio de Economía con relación a las razones que explicaban el déficit del organismo. Por un lado, el gobierno había asumido el compromiso de girar a PAMI un mínimo de \$200 millones mensuales (2400 al año) cubriendo con fondos propios la diferencia cuando la recaudación fuese menor. Aunque desde el Ministerio declaraban que transferían todo lo que correspondía a PAMI, desde el organismo aducían que el gobierno estaba incumpliendo, transfiriendo una suma menor, y que además había dos organismos estatales que debían, en conjunto, $\$ 130$ millones a PAMI. ${ }^{47}$

\footnotetext{
${ }^{44}$ Denunciaban que la intermediaria entre ellos y el PAMI (la empresa OMA, que dependía a su vez de $S I P R E N$ ) se quedaba con el $40 \%$ de la cápita con la que la clínica debía atender todos los servicios que le brinda al jubilado: médicos, traumatológicos, radiológicos, dentales, etcétera. Así, de una cápita de \$20, la clínica recibía $\$ 12$ y el anestesista alrededor de 40 centavos.

${ }^{45}$ Esto, gracias al decreto 996/98 firmado por el presidente. La toma de estos créditos no tendría garantía del Tesoro Nacional, pero se autorizaba a entregar como aval del endeudamiento la futura recaudación del PAMI, transfiriendo el problema de repago a la próxima gestión.

${ }^{46}$ Se pagaron a las farmacias $\$ 27,5$ millones, correspondientes a la deuda de agosto y se prometió acordar el pago de idéntica suma correspondiente a setiembre. Asimismo, la presidencia del PAMI prometió la creación de un bono del Estado para pagar los \$90 millones les debía a las farmacias desde abril de 1996.

${ }^{47}$ Afirmaban que la ANSSAL (Administración Nacional del Seguro de Salud) debía a PAMI unos $\$ 81$ millones (de los 220 que se acordaron en el decreto de normalización el año anterior). Y que también la Secretaría de Desarrollo Social adeudaba \$50 millones, por la atención que el PAMI les brindó a los afiliados de pensiones no contributivas que fueron transferidos a esa Secretaría.
} 
A comienzos de mayo de 1999, se produjo una nueva crisis de prestación de servicios. Las clínicas del conurbano comenzaron a atender sólo casos de emergencias en reclamo por falta de pagos mientras los demás establecimientos del interior disponían un cese de actividades de 48 horas. La Confederación Argentina de Clínicas, Sanatorios y Hospitales Privados (Confeclisa) -que reúne a 1600 clínicas del interior- reclamaba a PAMI más de \$200 millones, correspondientes a febrero y marzo. Desde PAMI reconocieron no estar al día con los pagos y culparon nuevamente al Ministerio de economía de incumplir el giro de \$200 millones mensuales. "Una fuente de PAMI" declaró a diario La Nación que en lo que iba del año 1999 los fondos girados no habían superado los \$165 millones por mes. El conflicto con las clínicas se destrabó dos días más tarde cuando el Gobierno le otorgó al PAMI \$40 millones para saldar parte de su deuda, consiguiendo con ello que prestadores médicos del PAMI levantaran la medida de fuerza. Sólo un mes después, los geriátricos y las clínicas psiquiátricas comenzaron a atender sólo emergencias de los afiliados de PAMI mientras las clínicas amenazaban con un paro generalizado debido al atraso de casi tres meses en los pagos. El propio Ministerio de Economía comenzó a ocuparse de gestionar un crédito para PAMI. ${ }^{48}$

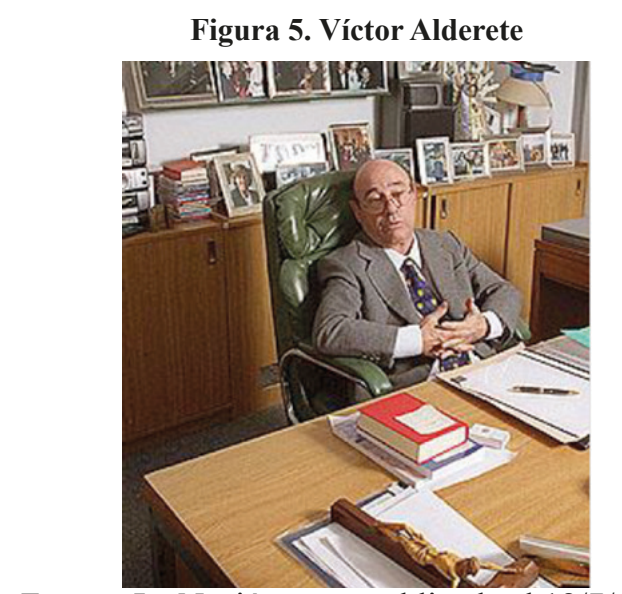

Fuente: La Nación, nota publicada el 18/7/1999.

A comienzos de julio, las clínicas del PAMI que atienden en el conurbano, junto con las clínicas psiquiátricas y los geriátricos de todo el país, suspendieron los servicios en reclamo por el pago de las deudas atrasadas de PAMI. 6 días después continuaba el paro y se sumaba la Asociación de Farmacias Mutuales y Sindicales de la República Argentina, que anunció que no brindaría medicamentos a los jubilados. El paro duró 15 días, hasta que PAMI anunció que 13 bancos se habían comprometido a concederle un

\footnotetext{
${ }^{48}$ A pesar de la crítica situación financiera de PAMI, a finales de junio Alderete dio a conocer su libro "PAMI. Una transformación necesaria", del que se editaron 3000 ejemplares, de 217 páginas, con un costo total de $\$ 42$ mil a cargo de PAMI. Allí realizaba un balance de su gestión y argumentaba "le ahorramos 400 millones al PAMI".
} 
Minoldo. La era menemista del PAMI. Una aproximación al pasado reciente de la obra social de los jubilados en...

crédito de $\$ 136$ millones $^{49}$ con el que PAMI pagaría las deudas atrasadas y cubriría el balance negativo de tres meses. Sin embargo, la entrega del dinero se demoró debido a algunos desacuerdos. ${ }^{50}$ El 28 de agosto las 54 clínicas de la Camfre volvieron a parar, en reclamo de $\$ 30$ millones correspondientes a junio y julio, pero también debido a un conflicto relacionado con la contratación de intermediarias y la baja a numerosos centros de rehabilitación que realizó PAMI cuando la controversia tomó tintes judiciales por una demanda contra PAMI. No fue hasta el 10 de septiembre, cuando el paro llevaba ya dos semanas, que los bancos desembolsaron un adelanto del crédito para PAMI, que debería devolver en tres años, con la garantía de que los bancos podrían cobrar las cuotas sin importar cuál fuera el desempeño del organismo, y contando además la garantía del tesoro nacional. ${ }^{51}$

En medio del conflicto, la controversia entre PAMI y el ministerio de Economía se endureció. A mediados de agosto se hizo público el contenido de un informe de la cartera de Hacienda, basado en un monitoreo del Programa de Reconversión de Obras Sociales, financiado por el Banco Mundial. Allí se afirmaba que el PAMI había recibido en el primer semestre del año más fondos de los recibidos en igual período del año previo. Así, mientras en 1998 había recibido un promedio mensual de $\$ 210$ millones, en 1999 esa suma se había elevado a \$221 millones. Desde PAMI, sin embargo, un vocero de Alderete insistió en que sólo habían recibido un promedio mensual de \$172 millones netos en 1999, luego de los descuentos que se destinaban a otras obras sociales. Desde PAMI argumentaban que la diferencia se explicaba porque Hacienda en sus números agregaba el aporte que recaudaba por los 450.000 jubilados afiliados a obras sociales sindicales, fondos que el PAMI remitía a las mismas, y que, además, contabilizaba créditos obtenidos para cubrir los baches de meses previos.

La primera semana de noviembre los conflictos con las prestadoras volvieron a activarse. Desde el 8 de ese mes, la Federación Argentina de Cámaras de Farmacias y la Confederación Farmacéutica Argentina anunciaron que las farmacias de todo el país dejarían de entregar medicamentos a los afiliados al PAMI (en reclamo de 60 millones). ${ }^{52}$ Los farmacéuticos sólo resolvieron levantar la medida 10 días después, cuando se supo que un grupo de once bancos prestaría $\$ 50$ millones al PAMI, que serán utilizados para saldar deudas atrasadas.

\footnotetext{
${ }^{49}$ Inicialmente, nueve bancos se comprometieron a prestar $\$ 100$ millones. Con el paso de los días, se sumaron otras cuatro entidades, con $\$ 36$ millones.

${ }^{50}$ Para entregar el préstamo los bancos reclamaban que un tercero asegurase que los ingresos del PAMI serían utilizados para pagar el crédito y no para cancelar otras deudas. Querían algún tipo de garantía adicional dado que el crédito, lejos de resolver los problemas de PAMI, incrementaría su déficit al estar obligado a pagar cuotas a los bancos. Según diario La Nación (en una nota del 15.7.1999), la participación de los bancos se explicaba menos como un buen negocio que como una clara expresión de apoyo al programa económico del gobierno, considerando que el préstamo se hacía a una tasa anual variable (en dólares) de $14,43 \%$, por debajo del $20 \%$ que por esos días los bancos prestaban a la Tesorería.

${ }^{51}$ Los prestamistas obtuvieron una autorización del BCRA para darles un carácter especial a los fondos prestados y un aval de la AFIP para que pudieran (si PAMI no pagaba) cobrarse la deuda no depositando sus cargas sociales. Para habilitar el mecanismo fue necesario además el acuerdo de la ANSES (donde se depositan los aportes para el PAMI).

${ }^{52}$ Para prevenir problemas en la provisión de medicamentos, la obra social creó una red de emergencia por medio de las farmacias mutuales y sindicales del PAMI.
} 
Figura 6. Suspensión de prestaciones a los afiliados de PAMI en 1998-1999

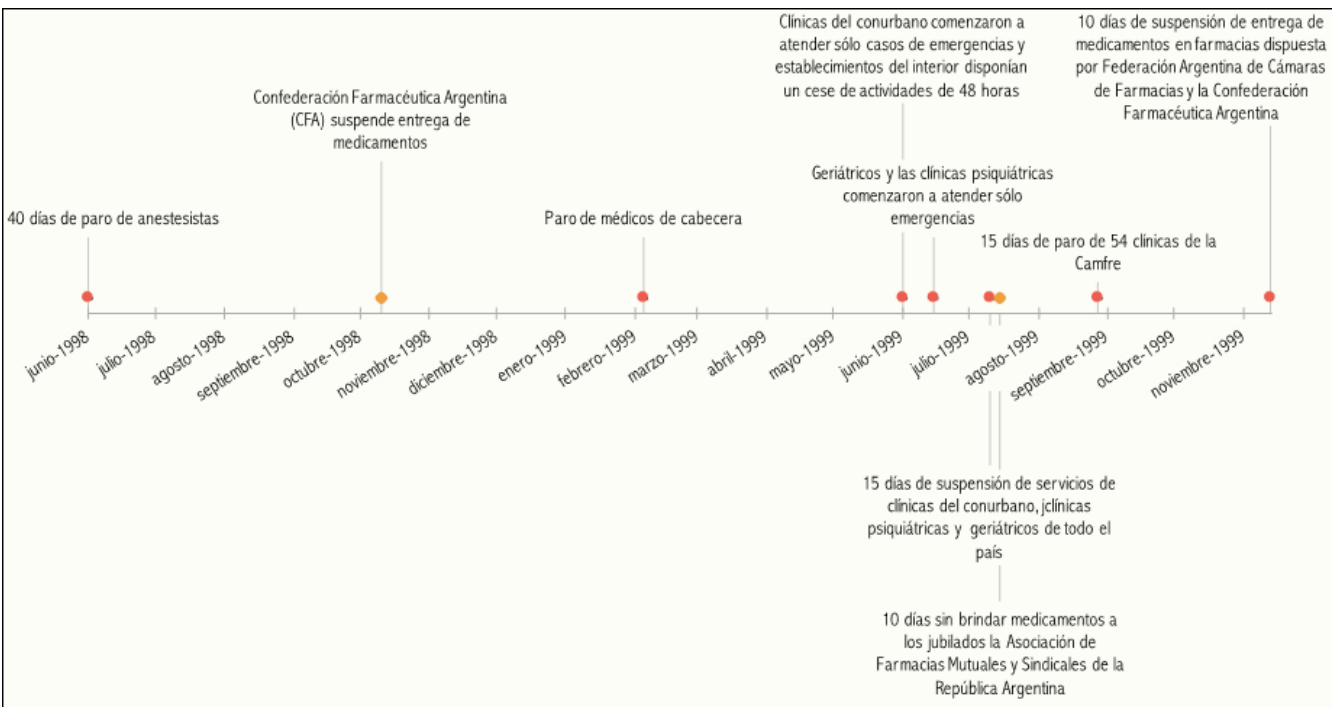

Fuente: Elaboración propia en base a notas de La Nación, Clarín y Página12, entre 1998 y 1999.

\section{Hacia el final de la era Alderete: una transición con controles y "regalos" de despedida}

A comienzos de noviembre de 1999 ya había sido electo presidente Fernando de la Rúa. Para preparar la transición, un equipo técnico a su cargo comenzó a investigar contratos, deudas, prestaciones y recursos humanos de la gestión de Víctor Alderete. ${ }^{53}$ El 8 de noviembre daban a conocer que, en función de los documentos analizados, en la obra social ingresan cerca de $\$ 70$ millones más por mes de lo que aseguraba Alderete. Por un lado, Alderete les había entregado información en al que aseguraba que PAMI recibía \$177 millones en promedio por mes. Por otro, informes internos del PAMI daban cuenta de ingresos en la obra social de al menos 248 millones mensuales.

Por otro lado, el 11 de noviembre un grupo de diputados del partido electo (la Alianza) adelantó que heredarían de la gestión menemista de PAMI una deuda de $\$ 1800$ millones. Es que, a la deuda contraída con bancos y prestadores por el PAMI desde su normalización, se sumaban pagos pendientes de $\$ 580$ millones de la deuda anterior de PAMI que había asumido el Estado.

Mientras tanto, la AGN había comenzado a auditar la obra social. Sin embargo, las auditorías sólo llegaban hasta 1998 y los aliancistas temían que el siguiente titular de la AGN -que sería nombrado por la oposición- no llegara al fondo con la investigación. ${ }^{54}$

\footnotetext{
${ }^{53}$ El equipo formado por De la Rúa para el área social estaba encabezado por Felgueras y también lo integran Rodolfo Rodríguez, Eduardo Bustello, Aldo Isuani, Pablo Vinocoud, Laura Goldberg y María Orsenigo.

${ }^{54}$ El nuevo presidente de la AGN designado en nombre del principal partido opositor sería Barra, nombrado en una carta firmada por Menem y Eduardo Bauzá, a quien la Alianza acusaba de conflicto de intereses
} 
Minoldo. La era menemista del PAMI. Una aproximación al pasado reciente de la obra social de los jubilados en...

Ya a comienzos de octubre, con la perspectiva del inminente desplazamiento de Alderete luego de las elecciones, ${ }^{55}$ PAMI dispuso pasar a su planta permanente a todo su personal contratado a través de la resolución 68. Según La Nación, ello alcanzaba 2000 nombramientos mientras que Página 12 refería a 1300 empleados. ${ }^{56}$ Vale recordar que la gestión de Alderete había invertido sumas millonarias para pagar retiros voluntarios destinados a reducir el personal de PAMI. En numerosos actos públicos (e incluso en su libro), Alderete había mencionado como un logro el hecho de haber disminuido el plantel y de haber saneado el instituto. Por otro lado, a días del cambio de gobierno, en un documento con fecha del 3 de diciembre, Alderete recategorizó a los empleados que tenían de tres a diez años de antigüedad en el instituto. La medida implicaba modificaciones en los niveles de sueldo y fuentes del PAMI aseguraban que eran cerca del $50 \%$ los empleados afectados por la recategorización.

\section{EI desalojo de Alderete}

Cuando, luego de asumir el nuevo gobierno, se dispuso la intervención de PAMI, Alderete no estaría allí: el 13 de diciembre solicitó licencia. Por medio de un comunicado, el directorio hizo público su rechazo a la posibilidad de intervención. La misma actitud asumió la CGT, que ordenó a sus representantes en el directorio que "permanezcan en sus puestos" a pesar de la anunciada intervención. Finalmente, el 15 de diciembre fueron nombrados, por decreto, los nuevos interventores: Cecilia Felgueras, que también haría de coordinadora, Ángel Domingo Tognetto y Horacio Rodríguez Larreta.

Figura 7. Rodríguez Larreta, Felgueras y Tonietto

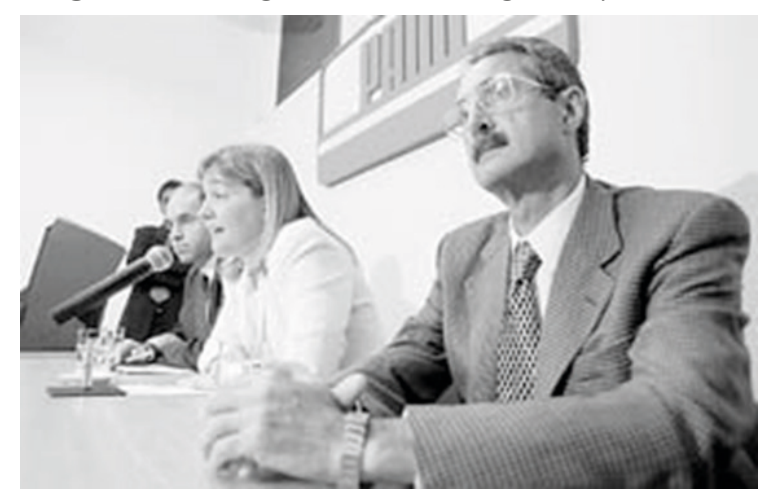

Fuente: Página 12, nota publicada el 27/1/2000.

por haber asesorado a empresas vinculadas a la prestación de servicios públicos que ahora debían ser auditados. También era acusado de antecedentes filonazis.

${ }^{55}$ Alderete no se llevaba bien ni con el duhaldismo ni con la Alianza. Así, ganara quien ganara, los nuevos compromisos que aceptara el PAMI pasarían a ser problema del sucesor de Alderete.

${ }^{56}$ La Asociación de Trabajadores del Estado (ATE) denunció que, entre las personas que acaban de ser incorporadas, figuraban "500 a 1000 punteros políticos" y que integrantes del directorio del PAMI se autonombraron como planta permanente de la obra social con sueldos de más de $\$ 4000$ mensuales cada uno, entre los que figurarían parientes de Alderete. 
Cuando la Comisión interventora normalizadora se instaló en la sede de PAMI, habían sido sustraídas al menos 96 cajas con documentación que días después serían secuestradas en un departamento del centro de Morón, propiedad de una secretaria de Alderete. Según fuentes judiciales, el traslado de la documentación había sido supervisado personalmente por el propio Alderete cuatro días antes de la asunción del presidente Fernando de la Rúa. Alderete, por su parte, aseguró que las cajas descubiertas por la Justicia contenían "sólo documentación y efectos personales que ninguna vinculación tienen con la vida institucional" de la obra social. Entre la documentación secuestrada se encontraron informes de inteligencia que, presuntamente, Alderete ordenaba realizar sobre los que criticaban su gestión.

La nueva conducción de PAMI suspendió, con su segunda resolución, el aumento de sueldo que el ex titular de la obra social había dispuesto con su medida de recategorización que, se supo entonces, alcanzaba a 6000 empleados, e implicaba un gasto adicional de $\$ 18,2$ millones al año.

Tognetto, uno de los interventores en el PAMI, aseguró que en la información que auditaban habían encontrado "sobreprecios en muchas contrataciones, con hasta dos y tres veces el valor de mercado".

\section{Reflexiones finales}

El relato de la prensa permite reconstruir varias dimensiones del desempeño de PAMI durante el gobierno menemista. Por un lado, encontramos información acerca de la forma de gobierno del instituto: luego de un período conducido por un directorio y presidenta designada por el gobierno, comenzó en 1994 un ciclo de sucesivas intervenciones en el organismo. Finalmente, la normalización del instituto se materializaría en 1997, y el gobierno designaría como presidente al último interventor, Víctor Alderete.

Otra cuestión que puede apreciarse se vincula con la forma de gestión de los servicios de salud y las modalidades de pago. Así, Menéndez instauraría un sistema de pago por cápitas que, si bien suponía la ventaja de evitar los fraudes por sobreprestación y de hacer predecibles las erogaciones de PAMI, permitiría que los prestadores incrementaran los niveles de ganancia a costa del deterioro de los servicios prestados. Este factor se incrementaría al implementarse el sistema de prestaciones mediado por empresas gerenciadoras, con el modelo de Alderete, que se aseguraban un ingreso fijo, dependiendo su rentabilidad de cuán poco consiguieran gastar en contratar a los prestadores.

Un rasgo sobresaliente de la era menemista de PAMI es el ciclo de endeudamiento creciente que se inicia con la gestión de Menéndez y recrudece fuertemente en los años sucesivos. A pesar que los ingresos del instituto habrían tenido una estabilidad garantizada por el tesoro nacional, que financiaba los saldos faltantes para alcanzar el mínimo garantizado para PAMI, y que por tanto no se pudo ver afectado por caídas en los niveles de recaudación, el déficit crónico de PAMI llevó a dificultades para afrontar 
Minoldo. La era menemista del PAMI. Una aproximación al pasado reciente de la obra social de los jubilados en...

el pago a los prestadores que resultaron en múltiples conflictos con interrupción de las prestaciones a los jubilados.

Sobresale, también, la intención de promover en PAMI un plan de ajuste que, a tono con las políticas económicas de la época, apuntaba a resolver el déficit mediante la inclusión de empresas privadas en la administración y el ajuste de personal propio (a pesar que los gastos de personal fuesen marginales en el presupuesto de PAMI). Mientras tanto, la prensa daba cuenta de decenas de denuncias de corrupción, fraudes, coimas y sobreprecios, que llegaron a su nivel más extremo durante la gestión de Víctor Alderete. Así, llegamos al último de los ejes que sobresale en este relato, y que se vincula con la falta de transparencia de la administración del instituto, que recrudeció durante la gestión de Alderete quien, escudándose en la autonomía de PAMI respecto del gobierno, se negó a permitir las auditorías de la AGN o consultoras externas, mantuvo ocultos los informes de la última auditoría que llegó a realizarse, recurrió contantemente a mecanismos de adjudicación directa y, cuando realizó una licitación, lo hizo en condiciones de falta de transparencia que llevaron a que la justicia obstaculizara su concreción.

En definitiva, encontramos que el constante déficit de PAMI parecería explicarse por los fraudulentos manejos de algunas de sus conducciones, de las empresas intermediarias y de algunos prestadores, costando al Estado un presupuesto mucho mayor al asignado, la contracción de numerosas deudas, y sin que este incremento de recursos evitara el deterioro e incluso intermitente interrupción de las prestaciones de PAMI a los jubilados del país, así como la crisis de un sector de salud fuertemente dependiente de los pagos de PAMI.

La información reconstruida en este trabajo constituye apenas un punto de partida para abordar el estudio del instituto. En tal sentido, a futuro sería importante respaldar y en lo posible profundizar los datos difundidos por la prensa, mediante fuentes de tipo administrativas. Esta primera aproximación constituye, sin embargo, un posible hilo conductor y una fuente de pistas para localizar incidentes relevantes, en función de los diferentes intereses teóricos desde los que se pretenda realizar el análisis. Por otra parte, el verdadero potencial del trabajo aquí expuesto reside en aportar información empírica para el análisis de la atención de la salud de personas mayores en Argentina, en el marco de discusiones sobre el derecho a la salud de las personas mayores, cobertura de salud en general o incluso políticas de seguridad social en general. 


\section{Referencias bibliográficas}

\section{Fuentes}

Página 12 (2018). 33 artículos publicados relacionados con PAMI, entre febrero de 1994 y diciembre de 1999, disponibles en www.pagina12.com.ar

La Nación (2018). 247 artículos publicados relacionados con PAMI, entre febrero de 1994 y diciembre de 1999, disponibles en www.lanacion.com.ar

Clarín (2018). 63 artículos publicados relacionados con PAMI, entre febrero de 1994 y diciembre de 1999, disponibles en www.edant.clarin.com.ar y www.clarin.com.ar

\section{Bibliografía}

Alderete, V. (1999). PAMI, una transformación necesaria. Buenos Aires: PAMI.

Anlló, G. y Cetrángolo, O. (2007). "Políticas sociales en Argentina: viejos problemas, nuevos desafíos". En Kosacoff, B. (ed.) Crisis, recuperación y nuevos dilemas. La economía argentina. 2002-2007.CEPAL 2007. Santiago de Chile

Belmartino, S. (2005). "Una Década de Reforma de la Atención Médica en Argentina". En: Revista Salud Colectiva, La Plata, 1(2): 155-171.

Bursztyn, I.; Kushnir, R.; Giovanella, L.; Stolkiner, A.; Sterman-Heimann, L.; Riveros, M. I. y Sollazzo, A. (2010). "Notas para el estudio de la Atención Primaria en contextos de sistemas de salud Segmentados”. En: Revista Salud Pública. 12 (1): $77-88$

Comisión Americana de Adultos Mayores (2002). "Salud en la Argentina. Atención del adulto mayor". XX Asamblea de la Conferencia Interamericana de la Seguridad Social, s/d.

Chiara, M. (2012). "Paradojas de la descentralización en salud en el Gran Buenos Aires, Argentina. Derroteros de la construcción de política sanitaria en un escenario local". En: Revista POSTData: Revista de Reflexión y Análisis Político, 17(2), 199-236.

Del Boca, V. y Rolleri, G. (2009). El Estado de las Contrataciones 2: estudio en profundidad de contrataciones públicas. Buenos Aires: Ministerio de Justicia, Seguridad y Derechos Humanos, Oficina Anticorrupción; PNUD Argentina; Embajada Británica, Recuperado de https://www.argentina.gob.ar/sites/default/ files/libro_mapa_2da_parte.pdf

Espínola, B. (2005). "Avances en el cumplimiento del plan internacional de Madrid sobre el envejecimiento, Argentina". Reunión de Gobiernos y Expertos sobre Envejecimiento de Países de América del Sur. Gerencia de Promoción Social y Comunitaria del INSSJP de la Rep. Argentina, Ministerio de Desarrollo Social de la Nación. CEPAL-CELADE, División de Población.

Golbert, L. (1988). "El envejecimiento de la población y la Seguridad Social”, Boletín informativo Techint, 251

Guido, P. (2003). "Reforma integral del Estado Nacional. Bases para un Estado limitado". Fundación Atlas para una Sociedad Libre. Buenos Aires. 
Minoldo. La era menemista del PAMI. Una aproximación al pasado reciente de la obra social de los jubilados en...

Gragnolati, M.; Rofman, R.; Apella I. \& Troiano, S. (2014). Los años no vienen solos. Oportunidades y desafíos económicos de la transición demográfica en Argentina. Buenos Aires: Banco Mundial, Recuperado de: http://www.danielmaceira.com. ar/wp-content/uploads/2014/07/Los-anios-no-vienen-solos-WB-libro.pdf

Infoleg (2018). Decreto 925/96, Recuperado de http://servicios.infoleg.gob.ar/ infolegInternet/anexos/35000-39999/38507/norma.htm

INSSJP (2012). "Informe Instituto Nacional De Servicios Sociales Para Jubilados Y Pensionados - PAMI". En Tercera Conferencia Regional Intergubernamental sobre Envejecimiento en América Latina y el Caribe. San José de Costa Rica, 8 al 11 de mayo de 2012. Disponible en http://www.cepal.org/celade/noticias/ paginas/9/46849/argentina_inssjp.pdf [octubre 2014]

Lloyd-Sherlock, P. (1997). Evaluando el impacto en el bienestar del Programa de Atención Médica Integral (PAMI). University of East Anglia, School of Development Studies.

Maceira, D. (2003). Seguros Sociales de Salud en el Cono Sur: Experiencias y Desafios. Centro de Estudios de Estado y Sociedad. Disponible en http://www.danielmaceira.com.ar/wp-content/uploads/2014/07/segurosconosurmaceira-cedes.pdf [septiembre 2014]

Melitón, S.; Soulages, G.e \& Touloupas, C. (2002). "La Política de Medicamentos en el PAMI del 2002: En qué quedamos, modelo sanitario o modelo de mercado". En: Revista Gestión Salud, 2(4), 72-77.

Ocaña, G. (2007). Libro sobre PAMI de título desconocido, Recuperado de https://www. argentina.gob.ar/sites/default/files/libro_pami_final.pdf

PAMI (2012). "Informe Instituto Nacional de Servicios Sociales para Jubilados y Pensionados - PAMI". República Argentina. Plan de Acción Internacional de Madrid sobre el Envejecimiento. Seguimiento de la Declaración de Brasilia". San José de Costa Rica, 8 al 11 de mayo de 2012.

Politi, P. (s/d). "Ya está todo pago. Análisis comparativo de seguros de salud nacionales: Medicare /Medicaid versus PAMI". s/d

Redondo, N. \& Rivkin, A. (2002). "Desarrollo de un sistema de información centrado en los usuarios de un servicio de salud de ancianos". s/d.

Ronconi, L. (2002). "La seguridad social en Argentina". Centro de Estudios para el Desarrollo Institucional, Recuperado de http://www.monografias.com/ trabajos913/seguridad-social-argentina/seguridad-social argentina.pdf 